Florida International University FIU Digital Commons

$1-13-2014$

\title{
Switching Regression Estimates of the Intergenerational Persistence of Consumption
}

Sheng Guo

Department of Economics, Florida International University, sguo@fiu.edu

Follow this and additional works at: https://digitalcommons.fiu.edu/economics_wps

\section{Recommended Citation}

Guo, Sheng, "Switching Regression Estimates of the Intergenerational Persistence of Consumption" (2014). Economics Research Working Paper Series. 36.

https://digitalcommons.fiu.edu/economics_wps/36 


\title{
Switching Regression Estimates of the Intergenerational Persistence of Consumption*
}

\author{
Sheng $\mathrm{Guo}^{+}$ \\ Department of Economics
}

Florida International University

January 13, 2014

${ }^{*}$ I am grateful to Casey Mulligan for his guidance and support, as well as generously sharing his data. I would like to thank Gary Becker, Susanne Schennache, Jeffery Smith and three anonymous referees for helpful comments and suggestions. All remaining errors are mine. This article is a substantially revised version of Chapter 3 of my dissertation thesis finished at the University of Chicago.

${ }^{+}$Correspondence address: Department of Economics, Florida International University, 11200 SW 8th Street, DM 318A, Miami, FL 33199. Email address: Sheng.Guo@fiu.edu. Tel: 305-348-2735; Fax: (305)348-1524. 


\begin{abstract}
The influential economic theory of intergenerational transfers predicts a negative connection between credit constraints and intergenerational mobility of consumption. Existing work has used bequest receipt to signal a parent's access to credit markets when investing in his children's human capital. Yet measurement error in bequest receipt generates misclassification error and thus attenuation bias. Employing switching regressions with imperfect sample separation to deal with this error, we show that the intergenerational persistence of consumption in the U.S. for credit constrained families is much higher than for unconstrained families, contrary to what the theory implies. This means children from constrained families are more likely to have consumption levels similar to those of their parents than children from unconstrained families. Our results are robust to the choice of bequest variables and other predictive variables in the switching equation.
\end{abstract}

JEL Classification: C13, D12, E21, J62

Key Words: Intergenerational Persistence, Intergenerational Mobility, Consumption, Borrowing Constraints, Switching Regression, Misclassification Error, Euler Equation 


\section{Introduction}

Since the seminal work of Friedman (1957) and Modigliani and Brumberg (1954), the fact that life-cycle consumption is much smoother than income has been established as one of the cornerstones in macroeconomics. Economic agents are able to optimize on their life-cycle consumption via the means of saving and borrowing. Similarly, family dynasties may be able to optimize on their lifetime consumption across generations through the channel of intergenerational transfers.

Yet, despite strong evidence of the massive intergenerational asset transfers (Kotlikoff and Summers, 1981), few studies - except perhaps Mulligan $(1997,1999)$ and Waldkirch et al. (2004) $)^{1}$ - have explored the intergenerational dynamics of consumption. In contrast, there is a large body of estimates on intergenerational relationships in income or earnings, for the United States and for other countries around the world. ${ }^{2}$

Investigating the intergenerational consumption relationship would complement our knowledge of the relationship of intergenerational income or earnings. Consumption is a more direct measure of economic wellbeing than income. Furthermore, understanding the intergenerational effects of parental financial transfers on consumption would be helpful for sensible public policy design. If parents are transferring resources in various forms (including financial transfers) in an optimal manner to promote their offspring's' overall wellbeing, then government transfer programs that target disadvantageous individuals at specific life stages through specific channels (e.g., education financial aids, or food stamp programs) may replace or crowd out parental inputs without achieving the same optimal effects on the overall wellbeing of these individuals.

Broadly, our study is linked to the question of how to interpret parental financial transfers

\footnotetext{
${ }^{1}$ Waldkirch et al. (2004) examined the intergenerational correlation in consumption due to the intergenerational linkages in income and tastes in a structural econometric framework, which in substance significantly differs from our model of interpreting and estimating the intergenerational consumption correlation.

${ }^{2}$ See the references in Mulligan (1997), and more recently, Chadwick and Solon (2002), Gaviria (2002), Ermisch et al. (2006), Mazumder (2005), Blanden et al. (2007), Bratsberg et al. (2007), Lee and Solon (2009).
} 
to their adult children. ${ }^{3}$ Financial transfers from parents can occur in the form of inter vivos (i.e., between living persons) gifts, ${ }^{4}$ or of bequests. ${ }^{5} 6$ The literature has debated on whether post-education financial transfers are driven by parental altruism, or by an exchange arrangement in return for services delivered or expected to be delivered from adult children. Previous studies have found evidence that inter vivos transfers are consistent with both motives (Cox, 1987, 1990), ${ }^{7}$ yet bequest transfers consistent with neither (Tomes, 1981; Wilhelm, 1996). McGarry (1999) showed that an altruistic parent makes inter vivos transfers to ease his child's liquidity constraints (therefore strongly related to her current income), and arranges bequest transfers in response to the child's permanent income (therefore only partially related to her current income).

More closely is our study linked to the view that treats bequest receipt as a signal of access to credit markets for human capital investments. Becker and Tomes (1986) argued that altruistic parents leave financial bequests to children only after they have made efficient human capital investments in their children. Under imperfect credit markets, there are credit constrained parents who cannot self-finance these investments without forgoing own consumption that has an opportunity cost higher than the market interest rate. This results in a lower consumption transmission from parents to children in constrained families.

Beside signaling access to credit markets, financial transfers including bequests enable

\footnotetext{
${ }^{3}$ Altonji et al. (1997) reported that, for instance, in PSID 1988 sample, the mean age of adult children who received positive transfer from parents is 29 , and the mean age of their parents is 58; only 2.9 percent of these children were still in school at the time of transfer.

${ }^{4}$ According to Altonji et al. (1997), the mean was \$1507.8 for the subset of PSID 1988 sample with positive amount of inter vivos transfer money. According to McGarry (1999), the mean of positive amount of inter vivos transfer money to each child (age 18 and over) was \$3013 from the Health and Retirement Study (HRS) 1992 survey, and was \$4215 from the 1993 Assets and Health Dynamics of the Oldest Old (AHEAD) survey.

5 "Inheritance" is more often used from the viewpoint of the recipient of a bequest. We use "bequests" or "inheritances" interchangeably throughout the paper.

${ }^{6}$ Hurd and Smith (2002) provided the size and distribution of actual bequests received by the children of the elderly surveyed in the 1993 AHEAD survey who passed away prior to the 1995 wave: more than $40 \%$ of children received nothing when their last surviving parent died; the mean size of inheritance is $\$ 18,600$, and only one in ten children collected $\$ 54,000$ or more.

${ }^{7}$ However, Altonji et al. (1997) found that the magnitude of inter vivos transfer is only $13 \%$ of what the parental altruism model implies.
} 
a parent to guard his offspring against any relative downward trending of consumption that arises from relative downward trending of lifetime income, thus contribute to a higher degree of persistence in consumption. From this perspective, the total welfare cost of credit constraints goes beyond what is revealed by education achievement or lifetime income, and the benefit of being born in a richer family is not limited to being able to afford elite education.

Our paper tests the connection between credit constraint and intergenerational consumption persistence, using bequest receipt as the signal of constraint status for the parental households. This test has been featured in Mulligan (1997, 1999). ${ }^{8}$ However, compared with Mulligan's work, we consider the possibility that the variable of bequest receipts is error-ridden when used as the signal, which may lead to misclassification of observations in estimation.

We employ switching regressions (SR henceforth) under imperfect sample separation to correct for the misclassification error. In terms of methodology, there has been only a couple of studies related to credit constraint in other contexts using SR with imperfect sample separation (Garcia et al., 1997; Jappelli et al., 1998). To our best knowledge, this is the first study to employ SR in estimating parameters of intergenerational mobility. ${ }^{9}$

One traditional limitation of SR models is that the error term under each switching regime has to be in specific classes of parametric distributions, in particular, the normal distribution. We show that this does not have to be the case: the SR model of two regimes, under the Monotonicity Condition (defined in Section 4), is identified when regime error terms exhibit any arbitrary distributions (see Appendix B). ${ }^{10}$

\footnotetext{
${ }^{8}$ Separately, Grawe (2010) tested the connection between credit constraint and family size effects, also using bequest receipt as the signal variable. He found contradictory evidence to the theoretical predictions.

${ }^{9}$ Nevertheless, the same framework has been used in a number of studies in other fields of economics, and Maddala (1986) provided an excellent survey by then. For instance, Lee and Porter (1984) used the SR model to test the price behavior under firm collusion in the industry, whereby the binary variable of whether firms are in collusion or not is at best imperfectly observed. Recent work by Kopczuk and Lupton (2007) employed the SR framework to signify the existence of significant bequest motives for the elderly that is difficult to detect from data otherwise.

${ }^{10}$ For the data we specifically examine, however, a normal distribution for each regime turns out to be adequate.
} 
Our SR estimates indicate that children raised in credit constrained parental households are more likely to have consumption levels similar to those of their parents than children from unconstrained parental households. Since constrained families on average consume less than unconstrained families, this implies their lower consumption (thus lower utility) will perpetuate into future generations. The SR model fits data better when compared with the simple sample splitting procedure. The SR estimates are robust to whether expected, or actual inheritance, or other various related variables are used for classifying constrained versus unconstrained families. The estimates are in contrast with the prediction for consumption from the theory, indicating the need of more work to deepen our understanding of the determinants of the intergenerational economic relationships.

The rest of this paper is organized as follows. Section 2 sketches the theory based on Becker and Tomes (1986). Section 3 describes the data (especially, the two bequest variables), and presents conventional sample splitting estimates. Section 4 sets up the SR model and presents SR results along with robustness checks. With estimates contradictory to the theory, Section 5 discusses possible alternative explanations. Section 6 concludes.

\section{The Economic Model of Intergenerational Mobility}

The estimation of intergenerational persistence of any kind of economic status, including consumption, is through the following regression:

$$
\log X_{c}=\text { constant }+\beta \log X_{p}+U
$$

where $X_{c}$ and $X_{p}$ are measurements of some economic variable of interest, such as consumption or earnings, for parents and children respectively. In literature, $\beta$ is often labeled as the intergenerational persistence, or the degree of intergenerational regression toward the mean, meaning how much of the economic difference among parents is bestowed onto their chil- 
dren; correspondingly, $1-\beta$ is referred to as the intergenerational mobility. Using logarithm of variables in (2.1) measures the difference on the relative rather than the absolute basis.

To interpret the size of $\beta$ in (2.1), we present here a simplified version of Becker-Tomes model assuming a perfect-foresight economy. Suppose individuals live through two consecutive time periods: childhood and adulthood. Each parent has exactly one offspring and his child's childhood overlaps with the parent's adulthood. The child has no role in human capital investment decision-making. By the time she grows up and starts working, the parent is assumed to pass away.

The parent decides how to allocate his resources between: (1) his own consumption; (2) his investment in his child's human capital; (3) the amount of financial transfer he is willing to pass onto his child. For the sake of simplicity, grandchildren have no explicit role in the model.

The budget constraint for the parent is:

$$
\begin{array}{r}
C_{p}+h+T=I, \\
T \geq 0,
\end{array}
$$

where $C_{p}$ is the level of parental consumption, $h$ is the human capital investment in his child, and $T$ is the financial transfer from parent to child. (2.2b) excludes the possibility for the parent to borrow against the child's future earnings, capturing the essence of credit constraints in a simple, tractable way. In reality, credit markets for human capital are imperfect because private education loan repayment entails limited enforcement for creditors, or because the private nature of information possessed by adult children in costly job searching or choosing their work efforts makes contracting on their future earnings difficult, ${ }^{11}$ or because of the possibility of "moral hazard" from parents in raising their own consumption by borrowing

\footnotetext{
${ }^{11}$ Lochner and Monge-Naranjo (2011) surveyed the literature that has incorporated these elements into quantitative models.
} 
and leaving substantial debts to their children.

The budget constraint for the adult child is

$$
C_{c}=(1+R) T+B h^{v}
$$

where $R$ is the intergenerational rate of return on financial assets, and $B$ is the child's innate ability. As we normalize the labor supply of everyone in the economy to one, the human capital production function $B h^{v}$ converts the investment amount and innate ability into the outcome of the child's earnings, where $0<v<1$ captures the characteristic of the diminishing rate of return from such an investment.

The parent cares about his own consumption as well as his child's: ${ }^{12}$

$$
\frac{\delta}{\delta-1} C_{p}^{\frac{\delta-1}{\delta}}+\alpha \frac{\delta}{\delta-1} C_{c}^{\frac{\delta-1}{\delta}}
$$

where $\alpha(>0)$ captures the degree of altruism of parent to child. $\delta(>0)$ is the elasticity of intergenerational consumption substitution. The parent's optimization problem is to maximize (2.4) subject to (2.2) and (2.3).

Let $\Delta=1$ if the borrowing constraint $(2.2 \mathrm{~b})$ is not binding (hence the parent transfers some assets to the child), and let $\Delta=0$ if otherwise (hence the parent makes no transfer of assets to the child). When $\Delta=1$, the efficient human capital investment amount is solved by equalizing the rate of return between human capital and non-human capital investment,

$$
v B h^{v-1}=1+R
$$

therefore

$$
h^{*}=\left(\frac{v B}{1+R}\right)^{\frac{1}{1-v}} .
$$

\footnotetext{
${ }^{12}$ This assumption, an alternative to assuming parents care about children's earnings/income, was invoked in some of the studies previously reviewed (Tomes, 1981; Cox, 1987, 1990; Altonji et al., 1997; McGarry, 1999).
} 
It follows that the threshold income for a family to be unconstrained, $I_{0}$, can be computed as

$$
I_{0}=h^{*}\left[1+\frac{(\alpha v)^{-\delta} B^{1-\delta}}{h^{*(1-\delta)(1-v)}}\right]
$$

Therefore the function for the indicator $(\Delta)$ of being unconstrained is

$$
\begin{cases}\Delta=1 & \text { if } I \geq I_{0} \\ \Delta=0 & \text { if } I<I_{0}\end{cases}
$$

Moreover, the amount of asset transfer from parent to child when the family is unconstrained can be solved out and expressed as

$$
T=\frac{I-h^{*}-(1+R)\left(h^{*} / v\right)(\alpha(1+R))^{-\delta}}{1+(1+R)[\alpha(1+R)]^{-\delta}}
$$

We solve for the consumption persistence equations for both constrained and unconstrained cases:

$$
\begin{aligned}
& \log C_{c}=\log C_{p}+\delta(\log \alpha+\log (1+R)) \quad \text { if } \Delta=1, \\
& \log C_{c}=\frac{v}{v+(1-v) \delta} \log C_{p}+\frac{\delta}{v+(1-v) \delta}(v \log (\alpha v)+\log B) \quad \text { if } \Delta=0,
\end{aligned}
$$

which suggests a system of regression equations for the consumption of these two types of families:

$$
\begin{array}{ll}
\log C_{c}=\beta_{1} \log C_{p}+U_{1} & \text { if } \Delta=1, \\
\log C_{c}=\beta_{0} \log C_{p}+U_{0} & \text { if } \Delta=0 .
\end{array}
$$

Since $0<\frac{v}{v+(1-v) \delta}<1$, the model predicts $\beta_{1}>\beta_{0}$ in (2.9). It is helpful to understand (2.9) with the patterns of intergenerational earnings mobility in mind. For unconstrained 
(richer) families, there is more often a downward regression towards the mean in the earnings of their children; for constrained (poorer) families, there is more often an upward regression. In the case of a downward regression in children's earnings, unconstrained parents could bequeath assets to offset the otherwise implied downward regression in their children's consumption, and constrained parents could not afford to do so. In the case of an upward regression in children's earnings, which would lead to an upward regression in their consumption without the need of asset transfers, the fact that constrained parents are unable to borrow against their children's earnings implies the upward regression of consumption of their children goes unfettered. To summarize, the absence of borrowing constraint slows down the degree of regression towards the mean for intergenerational consumption, whereas the existence of borrowing constraint prevents such a slowdown to occur. Thus, $\beta_{1}>\beta_{0}$.

This empirical prediction on consumption $\left(\beta_{1}>\beta_{0}\right)$ is preserved when human capital investments are risky and this risk cannot be hedged away in financial markets, or there are heterogeneities in $\alpha, B$, or $v$ that are not systematically correlated with family income (Mulligan, 1997, 1999). The prediction would also be preserved in an otherwise identical, two-period model (with a working period and a retirement period), as long as the consumption in question is measured for the working period. This is because the within-period marginal utility of both the parent and the child is equalized intergenerationally, when a positive asset transfer occurs. ${ }^{13}$ However, it is unclear whether the predication would be affected, if the number of children is endogenously determined, or if assortative mating existing in the marriage market is taken into consideration.

Although it is not a focus of this paper, one may be concerned that the error terms in

\footnotetext{
${ }^{13}$ For a sketchy illustration, assume that there are two periods ( 1 and 2$)$ for both the parent and the child, and the second period of the parent overlaps with the first period of the child. For simplicity, assume the gross rate of return is one and the discount rate between periods is zero. $\alpha$ is still the parental altruism. The parent is maximizing

$$
U\left(C_{p, 1}\right)+U\left(I_{p}-T-C_{p, 1}\right)+\alpha U\left(C_{c, 1}\right)+\alpha U\left(I_{c}+T-C_{c, 1}\right),
$$

while the child is maximizing the sum of last two terms. The within-lifetime Euler equation for the parent is $U^{\prime}\left(C_{p, 1}\right)=U^{\prime}\left(C_{p, 2}\right)$, and for the child, $U^{\prime}\left(C_{c, 1}\right)=U^{\prime}\left(C_{c, 2}\right)$. When $T>0, U^{\prime}\left(C_{p, 2}\right)=\alpha U^{\prime}\left(C_{c, 2}\right)$. Therefore, $U^{\prime}\left(C_{p, 1}\right)=\alpha U^{\prime}\left(C_{c, 1}\right)$, which leads to an equation identical to (2.8a).
} 
subequations of (2.9), which are correlated to $I$ and hence $C_{p}$ as implied by (2.6), produce selection bias. Han and Mulligan (2001) quantitatively investigated this issue for a variety of numerical values of $\delta$, and find that this selection bias does not affect the relative magnitudes of $\beta_{1}$ and $\beta_{0}$, except when the $\delta$ is close to 0 , then $\beta_{1}$ and $\beta_{0}$ become difficult to distinguish from each other. Our results show $\beta_{1}$ and $\beta_{0}$ are indeed quantitatively and statistically different from each other.

\section{Data and Simple Sample Splitting Estimates}

To estimate (2.9), we need parents' and children's consumption at comparable ages and an indicator of bequest transfer from parents to children. In addition, information on relevant socio-demographic characteristics is needed in order to hold these socio-demographic factors constant in the regressions. Mulligan $(1997,1999)$ tested the implications from Becker-Tomes model on a sample of 1781 parent-child pairs from the Panel Study of Income Dynamics (PSID), a longitudinal survey of U.S. individuals and their families. Starting in 1968, households in PSID were interviewed annually through 1997, and since then were interviewed biannually. When children grew up and left home to form their own households, these "child split-off" households were also tracked in subsequent interviews.

We use exactly the same sample as is in Mulligan $(1997,1999)$ for comparison of results. In this intergenerational sample, parents were surveyed in 1968-1972 and adult children were surveyed in 1984-1989 at comparable ages. Adult children already participated in the job market by the time of survey. Consumption is constructed as the weighted average of a household's expenditures on food at home, food away from home, rent and the value of the family's house. ${ }^{14}$ We refer readers to Mulligan $(1997,1999)$ for detailed description of the

\footnotetext{
${ }^{14}$ The weights are taken from Skinner's (1987) study which estimates the weights of these aforementioned individual consumption components by regressing total consumption on these individual components from Consumer Expenditure Surveys (CEX) data. This measure of "weighted consumption" is also employed in Waldkirch et al. (2004).
} 
sample selection and other aspects of the sample data.

For our purposes, we describe in detail below two types of bequest receipt variables expected versus actual inheritances - available in the PSID data, each plagued with its own source of measurement error. Gaviria (2002) reported the disparity in estimates of earnings persistence when he uses these two variables to split a PSID sample into unconstrained and constrained groups. ${ }^{15}$ Similarly, we find such a disparity in estimates of consumption persistence when using these two inheritance variables, which motivates the adoption of SR framework.

\subsection{Expected inheritances}

In 1984, PSID respondents were asked about how much inheritances they have received up to 1984 ,

(k150) Now we're interested in where people's assets come from. Have you (or anyone in your family living there) ever inherited any money or property? as well as how much they expected to receive in the future: ${ }^{16}$

(k157) What about future inheritances - are you fairly sure that you (or someone in your family living there) will inherit some money or property in the next ten years (emphasis added)?

Since only $9 \%$ of adult children in the sample did actually receive any inheritances at some point prior to 1984, for the sake of convenience we shall label the constructed variable

\footnotetext{
${ }^{15}$ Actually, his construction criterion for splitting the sample based on actual inheritances is a mixed one: whether children reported receiving more than \$10,000 inheritances/gifts in 1984-1989 or whether their parents had more than $\$ 100,000$ in wealth in 1988. Families satisfying either of these two conditions will be regarded as unconstrained. Using this indicator, Gaviria showed that the earnings or wage mobility is indeed higher in unconstrained than in constrained families in linear regressions, just as the Becker-Tomes model predicts. Our conventional linear regression results by using the indicator of actual inheritances also agree with the prediction of the Becker-Tomes model. Notwithstanding, Gaviria did acknowledge the limitation in relying on the wealth information: wealthy parents may fail to invest optimally in their children if they are not altruistic enough.

${ }^{16}$ More "unfolding brackets" questions about the amounts of inheritances would follow, if the respondent answered "Yes" to either of these two questions.
} 
from these two questions as the expected inheritance. This variable was used in Mulligan (1997) to classify the original parental households of 1968-1972 into constrained versus unconstrained groups. The justification for splitting up the sample by expected inheritances is that children who expected sizable inheritances from parents were unlikely to have had difficulty obtaining financial support for schooling, quality health care and other forms of human capital investment. ${ }^{17}$ Specifically, Mulligan used a fixed cut-off value of 25,000 dollars for expected inheritances to split the sample: those who expected to receive more than 25, 000 dollars are from unconstrained families, and those who did not are from constrained families. 1819

Based upon the expected inheritance survey questions above, if an interviewee was fairly sure that her wealthy parents would leave her a sizable bequest, but not sure that they would pass away in the next ten years, she would choose to answer "no" instead of "yes". In addition, the expected inheritance survey questions are not clear on whether gifts are supposed to be included. This sort of response error originates from the ambiguity in how respondents had interpreted the survey question. ${ }^{20}$ With these caveats in mind, we

\footnotetext{
${ }^{17}$ The parent's expectation about how much he is to bequeath to his child is more relevant based upon the model. Therefore, the implicit assumption here is that children's expectation coincides with parents' expectation.

${ }^{18}$ Note that tying the theoretical construct of borrowing constraint with a certain low range of observable financial or economic variables has a long history in the literature (Chetty, 2008; Gaviria, 2002; Mulligan, 1997, 1999; Runkle, 1991; Zeldes, 1989). Implicitly, what this assumes is that the sample units falling within the defined range are "more likely" to be borrowing constrained, a presumption to be explicitly formalized in this paper.

${ }^{19}$ Answering "no" or having all missing values in anticipated inheritance will be treated as zero. The key here is not about the distinction between zero and missing values, but about the group with large size of inheritance versus all else, i.e., all we need is that the group with sizable inheritances is more likely to be unconstrained than otherwise, including those with missing values. The possibility that missing-value observations are otherwise more likely to be unconstrained does not sit well with available evidence. Same applies to the actual inheritances/gifts measure to be introduced next. There are only a dozen of missing observations for expected inheritances, in contrast to over 700 missing observations for actual inheritances/gifts. Mulligan (1997, Table 8.6, Column 3 and 4) obtained the results almost identical to OLS ones by a Tobit model in regards to the expected inheritance measure. We experimented with a Tobit model of the consumption persistence regressions for the actual inheritance measure and also obtain results almost identical to those from OLS. Furthermore, in the robustness check (refer to pp.22), we estimated the SR model restricted to non-missing observations for the actual inheritance variable, and obtain similar results.

20 To investigate this issue, we examined the variable of parents' vital status (Deceased, Alive or N/A) as of 1984 and as of 1994 of the current sample. We found that the distribution of parental vital status for children who answered "Yes" to the expected inheritance question is roughly the same as that for those who answered "No." The majority of respondents anticipating that they would receive inheritances in years 1984 - 1994 had
} 
examine another piece of inheritance information - actual inheritances/gifts - from the same database.

\subsection{Actual inheritances/gifts}

In 1984-1999 (once every five years), and in 2001 and 2003, retrospective, follow-up questions regarding actual inheritances and gifts ${ }^{21}$ received are introduced. In the PSID 1989 survey the question of actual inheritances and gifts posed to the respondent is: ${ }^{22}$

(G228) Some people's assets come from gifts and inheritances. During the last five years, have you (or anyone in your family living there) received any large gifts or inheritances of money or property worth $\$ 10,000$ or more?

We use the sum of inflation-adjusted actual financial transfers received over the years up to 2003 to divide the observations into the unconstrained versus constrained group, adopting the same threshold value $\$ 25,000 .^{23}$ About $79.1 \%$ of these adult children have received zero or have missing values up to 2003. Figure 1 plots the distribution density of financial transfers received by those grown children who have received positive inheritances/gifts, from which we observe that $\$ 25,000$ is near the mode and mean of the distribution. Table 1 shows that a majority of adult children in the sample have neither anticipated nor actually received inheritances/gifts over the period of 1984-2003, and the proportion of those with actual inheritances/gifts more than $\$ 25,000$ is below 10 percent.

both of their parents alive in 1984 as well as in 1994, the same as the pattern for respondents who indicated that they were not anticipating any inheritances for the same period. Among the few respondents who had neither parent alive at the time of survey in 1984, some still expressed their anticipation of inheritances from somewhere. These suggest the data on expected inheritance are probably error-ridden due to response error. Notice that we do not claim that these expressed expectations from data are irrational, as there might be true surprises when it comes to the discrepancy between expected and actual inheritances. Our data does not allow us to set apart whimsical expectations from true surprises to rational expectations.

${ }^{21}$ Or "actual financial transfers", which we will use interchangeably.

${ }^{22}$ Once again, more "unfolding brackets" questions will follow regarding the size and the receiving year, if a respondent answers "Yes" to the survey question below.

${ }^{23}$ This is the same variable used in Grawe (2010) to study the connection between credit constraints and family size effects. 
This actual inheritance variable has its own caveats. One is the attrition. Although each year the attrition rate of the PSID sample is fairly small $(<5 \%)$, over the years, many cases of missing values have accumulated for actual inheritance/gift variable. Attrition affects the classification of an observation, for we code these attrition cases as if their actually received inheritances/gifts are less than $\$ 25,000$, which is not necessarily true. The misclassification due to this is analogous to the response error associated with expected inheritance. We examined whether attrition causes systematic discrepancy of some of the relevant variables for observations that have attrited in later years, as opposed to the ones that have not, by conducting Wilcoxon-Mann-Whitney tests. We found that observations from families with low consumption, with sons, and with single parents are more likely to disappear over the years, which favors our treatment of observations with missing values of inheritances to be more likely in the constrained group. ${ }^{24}$

The other caveat is that actual inheritances/gifts may contain financial surprises. Some parents happened to experience financial windfalls at later ages; ${ }^{25}$ in such cases, the actual inheritance/gift would diverge from what parents earlier intended to bequeath to children. This has similar impacts on estimation as those from respondents misreporting their expected inheritance. In any case, we certainly cannot rule out the sorts of aforementioned measurement error embedded in the variable.

Table 2 presents summary statistics for groups split by both inheritance variables. Parents ages are statistically, but not economically different between the subsample of sizable inheritances/gifts and the other. In families where adult children expected to or have received sizable inheritances/gifts, they enjoyed higher income, higher consumption and more schooling years, and their parents also enjoyed higher levels of consumption and income.

\footnotetext{
${ }^{24}$ Results are available upon request. Furthermore, SR results changed little when those attrition observations are excluded (see the Subsection 4.2).

${ }^{25}$ We will explore this issue in the section of discussion of our results. Nonetheless, missing observations for parents in their retirement years do not allow us to offer a complete answer.
} 


\subsection{Simple Sample Splitting Estimates}

Based upon the binary variable constructed from expected inheritances $\left(D_{e}=1\right.$ if a child expected a total inheritance amount of more than $\$ 25,000 ; D_{e}=0$ if otherwise), Mulligan (1997) estimated (2.9) for the sub-sample of $D_{e}=1$ versus $D_{e}=0$ directly, the procedure we name as the "simple sample splitting" to differentiate from SR that will be considered later. Children's household consumption is the dependent variable. Parental household consumption is the primary independent variable of interest, with covariates controlling for life-cycle effects. ${ }^{26}$ These covariates include the child's gender, the parental household head's and the adult children's age quadratics, their marriage status for the period when parents and adult children are respectively observed. For the sake of comparison, we follow his choice of covariates in our SR estimation. ${ }^{27}$

The main finding from Mulligan (1997) is that the unconstrained families do not seem to exhibit a higher degree of consumption persistence. In fact, if anything, the unconstrained families have a lower degree of persistence in consumption than the constrained ones $\widehat{\beta}_{1}=$ 0.45 versus $\widehat{\beta}_{0}=0.55$, see the two rightmost columns in Table 3 ), contrary to the prediction of our theoretical model. However, we obtain the opposite results when turning to the variable of actual inheritances/gifts to split the sample. Table 4 presents linear regression estimates from splitting the sample according to this variable $\left(D_{a}=1\right.$ if a child has actually received more than $\$ 25,000$ inheritances/gifts; $D_{a}=0$ if otherwise). Now we obtain something in line with the theory: we find $\widehat{\beta}_{1}=0.63$ for those likely to be unconstrained $\left(D_{a}=1\right)$ as opposed to $\widehat{\beta}_{0}=0.52$ for those likely to be constrained $\left(D_{a}=0\right){ }^{28}$

\footnotetext{
${ }^{26}$ Grawe (2006) discussed the estimation bias in intergenerational earnings persistence resulting from the deviation of observed earnings from lifetime earnings that varies with age.

${ }^{27}$ Notably, Mulligan (1997) did not include family size as one of the covariates. Implicitly, the Becker-Tomes model treats the number of children as a choice variable that is likely to be endogenous.

${ }^{28}$ These two sets of estimates are both statistically significant at 0.01 level in and by themselves. However, the difference between 0.45 and 0.55 , or the difference between 0.63 and 0.52 , is not statistically significant at 0.10 level.
} 


\section{Switching Regression Estimates and Robustness Checks}

Therefore, the estimates of intergenerational mobility of consumption are sensitive to which variable, the expected or actual inheritance, is used for classification. Guided by the theory, expected inheritances seem to be a better measure than actual inheritances to be used in the empirical test, for actual inheritances may be affected by parental later-life market luck that is associated little with earlier credit availability for investing in children. This justification, however, can be overshadowed, if the mis-measurement caused by the response error in expected inheritances is severe enough. A sound empirical approach is called upon to explicitly address the embedded measurement error.

Statistically, the insignificance between estimated $\widehat{\beta}_{1}$ and $\widehat{\beta}_{0}$ can possibly be attributed to the attenuation bias caused by the misclassification error. Interested readers can refer to Appendix A that proves how the attenuation bias is generated by by classical errors-invariables and by setting arbitrary cutoffs to divide the sample.

\subsection{Switching Regression Estimates}

Adopt the notation

$$
\operatorname{Pr}\left(\Delta_{i}=1 \mid D_{i}=1\right)=p_{1}, \quad \operatorname{Pr}\left(\Delta_{i}=0 \mid D_{i}=0\right)=p_{0},
$$

where $\Delta_{i}$ is the true underlying indicator and $D_{i}$ is the observed indicator with misclassification error. The simple sample splitting estimates are only consistent when $p_{1}=p_{0}=1$.

If (4.1) is parameterized into

$$
\operatorname{Pr}\left(\Delta_{i}=1 \mid D_{i}\right)=F\left(\gamma_{0}+\gamma_{1} D_{i}\right)
$$

where $\gamma=\left(\gamma_{0}, \gamma_{1}\right)$ is the vector of parameters, then (4.2) is called the switching equation in the 
context of the SR framework and can be viewed as the probability equation of predicting $\Delta_{i}$ from the knowledge of $D_{i} \cdot{ }^{29}$

With misclassification, $0<p_{k}<1(k=0,1)$, the likelihood function derived from (2.9) will be

$$
\begin{aligned}
& f\left(\log C_{i, c} \mid D_{i}=1\right)=p_{1} f\left(\log C_{i, c} \mid \Delta_{i}=1\right)+\left(1-p_{1}\right) f\left(\log C_{i, c} \mid \Delta_{i}=0\right) \\
& f\left(\log C_{i, c} \mid D_{i}=0\right)=\left(1-p_{0}\right) f\left(\log C_{i, c} \mid \Delta_{i}=1\right)+p_{0} f\left(\log C_{i, c} \mid \Delta_{i}=0\right)
\end{aligned}
$$

The identification of parameters in the likelihood function (4.3) requires: $(1)\left(U_{1}, U_{0}\right)$ (called "regime error terms") in (2.9) belong to a specific family of distributions whose finite-mixture can be identified up to subscripts, notably normal distributions (Yakowitz and Spragins, 1968); (2) $p_{1}+p_{0}>1$ (named as the Monotonicity Condition following Hausman et al. $\left.(1998)^{30}\right)$, namely, relying on the imperfect proxy $D$ is better than without it to predict $\Delta$, a condition already implicitly present in the cited literature in Section 1 . As will be shown in the Appendix B, the Monotonicity Condition helps anchor the interpretation of subscripts, and thus completes the identification of parameters in the model. In our context, the Monotonicity Condition stipulates that those with a larger size of inheritance/gift are more likely to be in the unconstrained group of dynasties, an assumption inherited from the Becker-Tomes model.

Formally, following the literature (Quandt, 1972; Quandt and Ramsey, 1978; Kiefer, 1978, 1979; Lee and Porter, 1984), we define the switching regression (SR) model as follows:

Definition. The system of two-regime equations (2.9), along with the misclassification errors defined in (4.1), is a switching regression model, if:

1. The possibility of misclassification is non-trivial $-0<p_{k}<1(k=0,1)$;

\footnotetext{
${ }^{29}$ In practice, the predictor $D_{i}$ can be generalized to a vector of variables, as long as the Monotonicity Condition is applicable to at least one of the variables in $D_{i}$.

${ }^{30}$ Hausman et al. (1998) used this term to describe the restriction on misclassification error in the dependent variable of discrete choice models.
} 


\section{The Monotonicity Condition holds $-p_{1}+p_{0}>1$;}

3. The regime error terms $\left(U_{1}, U_{0}\right)$ follow one of the finite-mixture identifiable distributions.

We prove, in Appendix B, that the last assumption in the definition above can be relaxed, in that $U_{1}$ and $U_{0}$ can follow any arbitrary distributions and the model is still identified. This proof relies on the finding in Ferguson (1983) that any arbitrary distribution on the real line can be indefinitely approximated by a mixture of a countable number of normal distributions. This extension of identifiability of finite mixtures models is of particular practical interest, for the consistency of the maximum likelihood estimator (MLE) hinges critically on the correct specification of the distributions of error terms. Our identification result ensures that under our specific assumptions, if the distributions of error terms are misspecified, it is very likely the MLE algorithm will not converge or yield sensible estimates. Therefore one can adjust the number of mixtures upwards or downwards for $U_{1}$ or $U_{0}$ until obtaining the best fit of the data. ${ }^{31}$ The practical procedure for implementation of SR estimation is delegated to Appendix C. ${ }^{32}$

Using the same intergenerational sample from PSID, the SR estimates in Table 3 differ remarkably from those when the constructed indicator $D$ is used directly. According to our theoretical model, children anticipating sizable inheritance receipts are more likely to be in unconstrained families. However, our estimates indicate that constrained families have a higher consumption persistence rate of 1.05 as opposed to 0.44 for unconstrained families, larger than previous conventional estimates. The difference is also statistically significant. The coefficient for the unconstrained case is almost identical compared with that in the sample splitting OLS, for the majority of the population is unconstrained based upon our

\footnotetext{
${ }^{31}$ This is by no means to substitute for a formal statistical test of the number of mixtures or parameter values of the mixture components. However, as Garel (2007) has noted, theoretical results of testing against more than two-component mixtures are difficult to obtain.

${ }^{32}$ Even though $\left(U_{1}, U_{0}\right)$ in $(2.9)$ can be of any arbitrary distributions, we found normal distributions are adequate for our data in estimation. Expanding $U_{1}$ or $U_{0}$ further into mixture of two normals would lead to the estimate of one of the weights over 0.99 .
} 
estimation.

Meanwhile, the interpretation of $\operatorname{Pr}(\Delta=1 \mid D=1)-\operatorname{Pr}(\Delta=1 \mid D=0)$ reveals that the families whose children expect more inheritance are $7.4 \%$ more likely to be unconstrained than the others. The evidence taken as a whole suggests that those unconstrained families comprise over 80 percent of the population, which surprisingly is fairly close to Jappelli's (1990) findings that 19 percent of families are rationed in the credit market from directly observed data. ${ }^{33}$ We caution that this interpretation holds only if we still regard intergenerational transfer as the indicator of credit constraints.

Now, we turn to the SR estimation employing the actual inheritance/gift splitting indicator. Table 4 presents results both from linear regressions of simple sample splitting and from SR ( $D_{a}=1$ if a child received more than $\$ 25,000$ inheritances/gifts; $D_{a}=0$ if otherwise). In contrast to simple sample splitting estimates, the SR estimates are almost identical to the ones using expected inheritance splitting indicator: 0.44 for unconstrained and 1.02 for constrained. Without receiving sizable inheritances/gifts, the family will be unconstrained with probability 0.84 ; for families receiving sizable inheritances/gifts, this probability increases to 0.93 .

It may be useful to plot against each other the raw data of children's consumption, the simulated data of children's consumption based upon SR parameters, and the predicted values of children's consumption based upon simple splitting estimates. These are presented in Figure 2 and Figure 3. For each parent-child observation, we take the values of covariates, including the value of one of the inheritance indicators, as are given in the data, and generate consumption value according to our estimated coefficients and estimated distributions of the random errors. The resulting two figures show that the simulated data from SR fit raw data better than those from sample splitting OLS, especially in capturing the tails of

\footnotetext{
${ }^{33}$ The data in Jappelli's study did not include details about categories of the loans applied by these families, e.g., children's college education loans, as opposed to mortgage loans, therefore it is not clear whether and to what extent these loans are related to children's human capital investments.
} 
the distribution. All told, we believe our SR estimates, in its precision and the fit of data, represent an improvement over those in Mulligan (1997, 1999).

\subsection{Robustness Checks}

We performed a number of robustness checks. First, since SR does not treat each observation as definitely in one underlying group or the other, less sensitivity should be observed by arbitrarily choosing a threshold value (such as $\$ 25,000$ ) in SR estimates than in simple sample splitting estimates. We checked this aspect of robustness by looking into actual inheritances/gifts, for more non-missing, continuous values are available in actual inheritances/gifts than in expected inheritances. Table 5 presents the results. The cutoffs for actual inheritances/gifts are varied from $\$ 0$ to $\$ 50,000$ to see how the estimates would be affected. The most contrasting simple sample splitting estimates among all thresholds are the ones at the threshold of $\$ 40,000$ : 0.69 versus 0.52 . However, SR shows less sensitivity in estimates from varying threshold values: for unconstrained, it is always around 0.44; and for constrained ones, it is always around 1.0.

Second, we put the logarithm of actual inheritances/gifts into the switching equation of the regression. In Table 3 and 4 , the coefficient of the bequest receipt indicator is not statistically significant. This may be due to less variation in the dummy variable due to construction. Plus, a level of transfers from a particular household that signals a non-binding borrowing constraint does not necessarily indicate a non-binding borrowing constraint for another household. A uniform threshold across households with different levels of bequest receipts is not reflective of this difference. Direct deployment of the bequest receipt amount in a regression thus helps address this concern. We chose the actual inheritances/gifts variable for this exercise, for it has fewer bracketed or zero/missing values than does the expected inheritance variable. Table 6 presents the results. The persistence rate of consumption for the unconstrained is 0.44 and, for the constrained, 0.98 , not much different from the estimates 
obtained before. The coefficient for the continuous actual inheritance variable is negative and now statistically significant at $5 \%$ level. In fact, if both the dummy variable of expected inheritances and the logarithm of actual inheritances/gifts are put into the switching equation (not shown), the coefficient for the latter is still negative and significant at $10 \%$ level.

Third, one may be concerned about the effects of the attrition of adult children from PSID surveys on our results. 221 adult children of our sample were not observed in the 1994 survey; 753 were not observed in 2003. We estimated the same SR model on the sample exclusive of all these 753 observations. The persistence rate of consumption for the unconstrained is 0.45 and for the constrained, 1.17, the latter slightly greater than the benchmark. The coefficient for the actual inheritance variable is again negative and statistically significant at $5 \%$ level.

Fourth, we conducted the SR analysis for various subsamples of our data set. We estimated it on the subset of families wherein fathers are present in 1967-1971, the subset of sons only, the subset excluding SEO (Survey of Economic Opportunity) observations, ${ }^{34}$ and the subset of families without parents cohabitation change in 1967-1971. For these subsamples, the estimates for the unconstrained families range from 0.45 to 0.49 , and, for the constrained families, from 0.98 to 1.33 . Qualitatively, these results do not change the conclusion derived from the entire sample.

Last, we repeated the SR analysis by invoking a richer set of indicators in the switching equation. These indicators are determinants rather than direct measures of intergenerational transfers. Given that parental altruism and children's ability are not observed and are not controlled for by using these determinants, SR results using these indicators as switching variables may suffer from omitted variable biases. ${ }^{35}$ Table 7 presents the sets of included variables and their associated results. We still obtain a higher consumption persistence rate for constrained families than for unconstrained families, even though the magnitude for

\footnotetext{
${ }^{34}$ SEO oversamples low income households.

${ }^{35}$ For this point, one only needs to check the terms involved in $I_{0}$ of the choice equation (2.6), and the terms defined in $U_{1}$ and $U_{0}$ of the outcome equations (2.9).
} 
constrained families has dropped somewhat (as low as 0.76 in one case). Nonetheless, all switching variables predict the probability of being in one group versus the other as what we would expect: parents with adequate savings, owning one or more cars, or the mother having a college degree are more likely to be unconstrained; parental households with a nonwhite head, a head aged 50 and above, or more children in schools are more likely to be in the constrained group.

\section{Discussion}

Recall that our total consumption is a predicted measure out of a few individual components. The variance of predicted consumption is less than the true variance, which may generate upward bias when predicted consumption is used as one of the regressors. ${ }^{36}$ The $R^{2}$ for this consumption prediction regression is 0.724 (Skinner, 1987). A back-of-envelope calculation, starting from our estimates of 0.44 and 1.02, yields 0.32 versus 0.72 after taking the $R^{2}$ for this consumption prediction regression into consideration. 0.32 means only $3.3 \%\left(\approx 0.32^{3}\right)$ of difference in consumption between two great-grandparent households is predictably transmitted to their descendants of current generation (any other difference in current generation will be attributed to unpredicted "shocks" that have occurred during this time period); for the coefficient 0.72 , this percentage is $37.3 \%\left(\approx 0.72^{3}\right)$.

Why are our estimates contradictory to the theoretical predictions, in that 0.32 is related to unconstrained families instead, while 0.72 is related to constrained families? We examine several alternative interpretations of this finding under the Becker-Tomes framework.

First, could it be caused by any kind of heterogeneity unobservable in data, especially, the parents' preference? Mulligan (1997) argued that if the gap of intergenerational mobility between the unconstrained and constrained groups is to be eliminated, the parental altruism

\footnotetext{
${ }^{36}$ See Guo (2010) for a discussion about econometric issues involved in using the predicted consumption measure.
} 
has to be somehow negatively correlated with parental resources. If parental altruism is merely randomly heterogeneous, Han and Mulligan (2001, Figure 5) offered simulation evidence showing that the persistence rate for constrained families may over take that for unconstrained ones with a tiny margin, and the degree of intergenerational substitution elasticity for consumption, at the same time, has to be sufficiently small. Their quantitative evidence is not remotely adequate to account for the difference as large as 0.32 versus 0.72 .

Second, could it be caused by the fact that unconstrained parents spend a smaller fraction of consumption on foods? It is well known that the share of consumption on food will decline when income is increased. Our consumption measure is constructed not only by food expenditure, yet food expenditure is an essential component. For simplicity, suppose consumption is predicted from food expenditure alone. Let $f_{i, t}$ be the food expenditure for the family $i$ in generation $t, \tau$ the average food expenditure share of total consumption (which is presumably less for unconstrained families), and $\xi_{i, t}$ the idiosyncratic part of food expenditure share, then

$$
f_{i, t}=\tau \xi_{i, t} C_{i, t}
$$

Logarithmic version of which is

$$
\log f_{i, t}=\log \tau+\log \xi_{i, t}+\log C_{i, t}
$$

Now, if the prediction based on $\log f_{i, t}$, rather than $\log C_{i, t}$ itself, is directly used in intergenerational consumption persistence regressions, what matters is the variance and co-variance of $\log \xi_{i, t}$ within each of unconstrained and constrained groups, not the relative magnitude of $\tau$ between these two groups. That is, it has more to do with the variation in food shares within each group, rather than the level of food shares. More evidence is needed to consider this possibility. ${ }^{37}$

\footnotetext{
${ }^{37}$ We can investigate household consumption surveys (such as CEX, or recent years of PSID) for this issue, but again, the challenge is whether financial transfer variables (preferable to parental income or wealth) are available
} 
Third, could it be caused by failure of the Monotonicity Condition? Is it possible that those who received sizable inheritances/gifts are actually children of parents who were once borrowing constrained? These parents could not have spent more on their children early on, and chose sizable bequests/gifts later to compensate for their disadvantaged children. If so, actual inheritances should be positively correlated with measures of adult children's economic or financial needs, conditional on inheritances they had already expected to receive. For suggestive evidence we refer to Table 8. This table presents the correlations of actual inheritances/gifts with measures of adult children's economic wellbeing, ${ }^{38}$ conditional on parental income and the expected inheritance dummy variable..$^{39}$

Evident from Table 8, the size of actual inheritances/gifts is strongly positively correlated with children's education and wealth, conditional on expected inheritances and parental income. Owning a house is often associated with various financial and liquidity advantages (Sheiner, 1995; Engelhardt, 1996; Robst et al., 1999; Cooper, 2013), yet homeowners among adult children received more inheritances than non-homeowners. Likewise, having more kids to raise demands more financial resources, yet adult children with more kids received less transfers from their own parents. All these evidences suggest that compensation motive, if there is any, is of secondary effect and cannot reverse the signaling power of bequest receipts as an indicator of parents not being borrowing constrained, i.e., our original interpretation of the Monotonicity Condition.

Last, could it be because that earnings are more persistent in constrained families, and that consumption simply tracks each generation's earnings without intergenerational linkage? To address this concern we conducted similar analysis for earnings and wages. The SR

to divide the observations into the constrained versus unconstrained, even with more detailed consumption data.

${ }^{38}$ Note that these variables are mostly in negative correspondence with the degree of financial needs, e.g., higher income means less needs of financial help, other things equal.

${ }^{39}$ Since information is not available for most of these parents at the time of bequeathing, this regression should be interpreted with caution. A positive correlation between, say, parental wealth close to the time of bequeathing and children's wellbeing, would bias the estimates towards being more significant than the otherwise. Yet, insofar as late-age parental wealth is positively correlated with parental income and children's expected inheritances, this bias will be partially mitigated. 
model failed to detect the existence of two groups from our data of earnings or wages. ${ }^{40}$ The algorithm either never converged, or, even if it converged, the estimated coefficients for the two groups bore little difference. This is so even when we included the same sets of variables in the switching equation as those we have used for the consumption persistence estimation, or when we experimented with non-normal distributions for the error terms. Thus, our results on consumption cannot be attributed to consumption simply tracking generational earnings or wages.

In this regard, Waldkirch et al. (2004) estimated a structural model that assumes the consumption of each generation is a function of its own permanent income, but there will be correlations of consumption between parents and children even after parsing out the effects of own income on consumption. Interestingly, they found that, for families whose adult children did not receive financial transfers from parents, or did not receive financial help towards the down payment of a house-would-be "constrained" families according to our definition-the estimated transmission degree of this residual consumption is higher than that for the entire sample $(0.55-0.61$ versus 0.45$)$ (Waldkirch et al., 2004, Table 5, pp.373). ${ }^{41}$ This goes in the same direction as what has been shown for the consumption persistence from our sample, and one suspects the difference would be even larger if SR is called upon to correct for possible noise in the transfers data they use.

\section{Conclusion}

This paper applies SR to estimating the intergenerational consumption persistence for credit constrained and unconstrained families, in order to test a related implication of the Becker-

\footnotetext{
${ }^{40}$ Han and Mulligan (2001) used simulations to show that, should there be a lot of heterogeneity in earnings ability in the population, it would not be easy to detect earnings persistence between constrained and unconstrained families in regressions, even in the absence of the misclassification issue.

${ }^{41}$ Waldkirch et al. (2004, Table 5) also presented the results related to their defined "liquidity constrained" cases. But it is defined from the life-cycle viewpoint of adult children instead of intergenerational viewpoint of parents. And they simply define those with low income as liquidity constrained.
} 
Tomes model. Our focus is the issue that, if a family's access to credit markets for children's human capital investments - as signaled by bequest receipt - is imperfectly measured and contains misclassification error, resulting estimates will suffer from attenuation bias. By employing SR to account for this misclassification error, our estimates reveal that the intergenerational consumption persistence is higher for credit constrained families than for unconstrained families. This result indicates that adult children of credit constrained families are more likely to have consumption levels similar to their parents' than are children of unconstrained families. Estimates from SR fit data better and are robust over a number of various specifications.

Under the settings of our model, we relax the parametric assumptions for identification, which are often imposed by the traditional SR literature, although for our data, the normal distribution turns out to fit well for each underlying group. Our approach does require, however, that the misclassification error in $D_{i}$ is uncorrelated with error terms in each of the two regime equations. This assumption seems innocuous given our focus on data issues and we have not been alarmed to evidence suggesting the otherwise. This assumption can be relaxed if additional instrumental variables for the true status (Lewbel, 2007; Mahajan, 2006) or independently repeated measurements of the true status $(\mathrm{Hu}, 2010)$ are available. ${ }^{42}$

Then, why are our estimates contradictory to the theoretical predictions? We have discussed several possible explanations that can address this discrepancy between evidence and theory, yet none of them seems particularly attractive. More future research is needed to address this discrepancy.

\section{References}

Altonji, Joseph G., Fumio Hayashi, and Laurence J. Kotlikoff, "Parental Altruism and

\footnotetext{
${ }^{42}$ The variables of expected bequests and actual bequests, to the extent that they are repeated signal measures of binding credit constraint, are statistically highly correlated in our data. Therefore, Hu's (2010) approach cannot be directly implemented here.
} 
Inter Vivos Transfers: Theory and Evidence," The Journal of Political Economy, 1997, 105 (6), $1121-1166$.

Becker, Gary S. and Nigel Tomes, "Human Capital and the Rise and Fall of Families," Journal of Labor Economics, July 1986, 4 (3), S1-S39.

Blanden, Jo, Paul Gregg, and Lindsey Macmillan, "Accounting for Intergenerational Income Persistence: Noncognitive Skills, Ability and Education," The Economic Journal, 2007, 117 (519), pp. C43-C60.

Bratsberg, Bernt, Knut Røed, Oddbjørn Raaum, Markus Jäntti, Tor Eriksson, and Eva Österbacka, “Nonlinearities in Intergenerational Earnings Mobility: Consequences for Cross-Country Comparisons," The Economic Journal, 2007, 117 (519), pp. C72-C92.

Chadwick, Laura and Gary Solon, "Intergenerational Income Mobility Among Daughters," American Economic Review, 2002, 92 (1), pp. 335-344.

Chetty, Raj, "Moral Hazard vs. Liquidity and Optimal Unemployment Insurance," Journal of Political Economy, 2008, 116 (2), 173-234.

Cooper, Daniel, "House Price Fluctuations: The Role of Housing Wealth as Borrowing Collateral," Review of Economics and Statistics, 2013, 95 (4), 1183-1197.

Cox, Donald, "Motives for Private Income Transfers," The Journal of Political Economy, 1987, 95 (3), pp. 508-546.

- , "Intergenerational Transfers and Liquidity Constraints," The Quarterly Journal of Economics, 1990, 105 (1), pp. 187-217.

Engelhardt, Gary V, “Consumption, Down Payments, and Liquidity Constraints," Journal of Money, Credit and Banking, 1996, 28 (2), 255-271. 
Ermisch, John, Marco Francesconi, and Thomas Siedler, "Intergenerational Mobility and Marital Sorting," The Economic Journal, July 2006, 116, pp. 659-679.

Ferguson, Thomas S., "Bayesian Density Estimation by Mixtures of Normal Distributions," in M. Haseeb Rizvi, Jagdish S. Rustagi, and David Siegmund, eds., Recent advances in statistics : papers in honor of Herman Chernoff on his sixtieth birthday, New York: Academic Press, 1983, pp. 287-302.

Friedman, Milton, A Theory of the Consumption Function, Princeton University Press, 1957.

Garcia, Rene, Annamaria Lusardi, and Serena Ng, "Excess Sensitivity and Asymmetries in Consumption: An Empirical Investigation," Journal of Money, Credit and Banking, May 1997, 29 (2), 154-176.

Garel, Bernard, "Recent asymptotic results in testing for mixtures," Computational Statistics $\mathcal{E}$ Data Analysis, 2007, 51 (11), 5295 - 5304.

Gaviria, Alejandro, "Intergenerational Mobility, Sibling Inequality and Borrowing Constraints," Economics of Education Review, 2002, 21, 331-340.

Grawe, Nathan D., "Lifecycle bias in estimates of intergenerational earnings persistence," Labour Economics, 2006, 13 (5), 551 - 570.

_ , “Bequest Receipt and Family Size Effects," Economic Inquiry, 2010, 48 (1), 156-162.

Guo, Sheng, "The Superior Measure of PSID Consumption: An Update," Economics Letters, 2010,108 (3), $253-256$.

Han, Song and Casey B. Mulligan, "Human Capital, Heterogeneity and Estimated Degrees of Intergenerational Mobility," The Economic Journal, 2001, 111 (470), 207-243.

Hathaway, Richard J., "A Constrained Formulation of Maximum-Likelihood Estimation for Normal Mixture Distributions," The Annals of Statistics, 1985, 13 (2), pp. 795-800. 
Hausman, J. A., Jason Abrevaya, and F. M. Scott-Morton, "Misclassification of the Dependent Variable in a Discrete-response Setting," Journal of Econometrics, December 1998, 87 (2), 239-269.

Hu, Yingyao, "Identification and Estimation of Nonlinear Models with Misclassification Error Using Instrumental Variables: a General Solution," Journal of Econometrics, 2010, 144 (1), 27-61.

Hurd, Michael D. and James P. Smith, "Expected Bequests and Their Distribution," 2002. Working Paper 9142, National Bureau of Economic Research.

Jappelli, Tullio, "Who is Credit Constrained in the U. S. Economy?," The Quarterly Journal of Economics, February 1990, 105 (1), 219-234.

_ , Jørn-Steffen Pischke, and Nicholas S. Souleles, “Testing for Liquidity Constraints in Euler Equations with Complementary Data Sources," The Review of Economics and Statistics, May 1998, 80 (2), 251-262.

Kiefer, Nicholas M., “Discrete Parameter Variation: Efficient Estimation of a Switching Regression Model," Econometrica, March 1978, 46 (2), 427-434.

_ , “On the Value of Sample Separation Information," Econometrica, July 1979, 47 (4), 9971003.

Kopczuk, Wojciech and Joseph Lupton, "To Leave or Not to leave: The Distribution of Bequest Motives," Review of Economic Studies, January 2007, 74 (1), 207-235.

Kotlikoff, Laurence J. and Lawrence H. Summers, “The Role of Intergenerational Transfers in Aggregate Capital Accumulation," The Journal of Political Economy, 1981, 89 (4), pp. 706-732. 
Lee, Chul-In and Gary Solon, "Trends in Intergenerational Income Mobility," Review of Economics and Statistics, 2009, 91 (4), pp. 766-772.

Lee, Lung-Fei and Robert H. Porter, "Switching Regression Models with Imperfect Sample Separation Information-With an Application on Cartel Stability," Econometrica, March 1984, 52 (2), 391-418.

Lewbel, Arthur, "Estimation of Average Treatment Effects with Misclassification," Econometrica, March 2007, 75 (2), 537-551.

Lochner, Lance J. and Alexander Monge-Naranjo, “The Nature of Credit Constraints and Human Capital," American Economic Review, September 2011, 101 (6), 2487-2529.

Maddala, G.S., "Disequilibrium, Self-selection, and Switching Models," in Z. Griliches and M.D. Intriligator, eds., Handbook of Econometrics, Vol. 3, North-Holland, 1986, chapter 28, pp. 1633-1688.

Mahajan, Aprajit, "Identification and Estimation of Regression Models with Misclassification," Econometrica, 2006, 74 (3), 631-665.

Mazumder, Bashkar, "Fortunate Sons: New Estimates of Intergenerational Mobility in the United States Using Social Security Earnings Data," Revieww of Economics and Statistics, 2005, 87 (2), pp. 235-255.

McGarry, Kathleen, "Inter vivos transfers and intended bequests," Journal of Public Economics, 1999, 73 (3), $321-351$.

Modigliani, Franco and Richard Brumberg, "Utility Analysis and the Consumption Function: an Interpretation of Cross-section Data," in Kenneth K. Kurihara, ed., Post-Keynesian Economics, Rutgers University Press, 1954, pp. 388-436. 
Mulligan, Casey B., Parental Priorities and Economic Inequality, Chicago: University of Chicago Press, 1997.

_, "Galton versus the Human Capital Approach to Inheritance," The Journal of Political Economy, dec 1999, 107 (6), S184-S224.

Quandt, Richard E., “A New Approach to Estimating Switching Regressions," Journal of the American Statistical Association, 1972, 67 (338), 306-310.

_ and James B. Ramsey, "Estimating Mixtures of Normal Distributions and Switching Regressions," Journal of the American Statistical Association, 1978, 73 (364), 730-738.

Rice, John A., Mathematical Statistics and Data Analysis, 3rd ed., Belmont, CA: Thompson/Brooks/Cole, 2007.

Robst, John, Richard Deitz, and KimMarie McGoldrick, "Income Variability, Uncertainty and Housing Tenure Choice," Regional Science and Urban Economics, 1999, 29 (2), 219 - 229.

Runkle, David E., "Liquidity Constraints and the Permanent-income Hypothesis : Evidence from Panel Data," Journal of Monetary Economics, 1991, 27 (1), p73 - 98.

Schmidt, Peter, "An Improved Version of the Quandt-Ramsey MGF Estimator for Mixtures of Normal Distributions and Switching Regressions," Econometrica, 1982, 50 (2), pp. 501516.

Sheiner, Louise, "Housing Prices and the Savings of Renters," Journal of Urban Economics, $1995,38(1), 94-125$.

Skinner, Jonathan, "A Superior Measure of Consumption from the Panel Study of Income Dynamics," Economics Letters, 1987, 23 (2), 213 - 216.

Tomes, Nigel, “The Family, Inheritance, and the Intergenerational Transmission of Inequality," The Journal of Political Economy, 1981, 89 (5), 928-958. 
Waldkirch, Andreas, Serena Ng, and Donald Cox, "Intergenerational Linkages in Consumption Behavior," The Journal of Human Resources, 2004, 39 (2), pp. 355-381.

Wilhelm, Mark O., "Bequest Behavior and the Effect of Heirs' Earnings: Testing the Altruistic Model of Bequests," The American Economic Review, 1996, 86 (4), pp. 874-892.

Yakowitz, Sidney J. and John D. Spragins, "On the Identifiability of Finite Mixtures," The Annals of Mathematical Statistics, February 1968, 39 (1), 209-214.

Zeldes, Stephen P., "Consumption and Liquidity Constraints: An Empirical Investigation," The Journal of Political Economy, April 1989, 97 (2), 305-346.

\section{A The Misclassification due to Measurement Error}

This section demonstrates the misclassification caused by measurement error (due to response error, for example) in inheritance (expected or actual), T. In our definition of unconstrained families, positive inheritance is a one-to-one mapping to the unconstrained status in intergenerational investment for a particular observation indexed $i$

$$
\operatorname{Pr}\left(\Delta_{i}=1 \mid T_{i}>0\right)=1
$$

Suppose instead of observing $T$, we observe an error-riden variable $T^{*}=T-\varepsilon$, where $\varepsilon$ is variation free of $T$. Since $T^{*}$ cannot be negative in our setting, $\varepsilon \leq T$. Therefore for a particular value of $T$, the distribution of $\varepsilon$ is a truncated one, the probability density function of which is denoted by $f_{\varepsilon \mid \varepsilon \leq T}(\cdot)$.

Using $T^{*}$ instead of $T$ to classify gives us

$$
\operatorname{Pr}\left(\Delta_{i}=1 \mid T_{i}^{*}>0\right)
$$


Using the dummy indicator $D$ to represent the constraint status by employing $T^{*}$, for any particular $\varepsilon_{i}$, we have

$$
\begin{aligned}
\operatorname{Pr}\left(\Delta_{i}=1 \mid D_{i}=1, \varepsilon_{i}, T_{i}\right) & =\operatorname{Pr}\left(T_{i}>0 \mid T_{i}^{*}>0, \varepsilon_{i}, T_{i}\right)=\operatorname{Pr}\left(T_{i}>0 \mid T_{i}>\varepsilon_{i}, \varepsilon_{i}, T_{i}\right) \\
& = \begin{cases}1 & \text { if } T_{i} \geq \varepsilon_{i} \geq 0 \\
\frac{1-F_{T}(0)}{1-F_{T}\left(\varepsilon_{i}\right)} & \text { if } \varepsilon_{i}<0\end{cases}
\end{aligned}
$$

where $F_{T}(T)$ is the cumulative distribution function of $T$. Since $\varepsilon_{i}$ is unobservable, we integrate over its support for those with $T_{i}$

$$
\begin{aligned}
\operatorname{Pr}\left(\Delta_{i}=1 \mid D_{i}=1, T_{i}\right) & =\int_{-\infty}^{T_{i}} \operatorname{Pr}\left(\Delta_{i}=1 \mid D_{i}=1, \varepsilon_{i}\right) f_{\varepsilon \mid \varepsilon \leq T_{i}}(\varepsilon) d \varepsilon \\
& =1-F_{\varepsilon \mid \varepsilon \leq T_{i}}(0)+\left[1-F_{T}(0)\right] \int_{-\infty}^{0} \frac{f_{\varepsilon \mid \varepsilon \leq T_{i}}(\varepsilon)}{1-F_{T}(\varepsilon)} d \varepsilon \equiv p\left(0 ; T_{i}\right)
\end{aligned}
$$

whose value is between 0 and 1 under regular assumptions about the distributions of $F_{T}($. and $F_{\varepsilon}($.$) .$

We integrate (A.4) over $T_{i}$ for the subsample $D_{i}=1$, since $T_{i}$ is not directly observed:

$$
\operatorname{Pr}\left(\Delta_{i}=1 \mid D_{i}=1\right)=\int_{T_{i}} p\left(0 ; T_{i}\right) d F\left(T_{i}\right)
$$

which is still between 0 and 1. This means the subsample of $D_{i}=1$ will be a mixed group including both $D_{i}=1$ and $D_{i}=0$ observations. Lee and Porter (1984) have proved that such a misclassification will lead to attenuation bias in estimated $\beta_{1}$.

Studies on liquidity constraints (Zeldes, 1989; Runkle, 1991; Mulligan, 1997) arbitrarily specify a positive cut-off value instead of 0 . Therefore instead of (A.2), we have

$$
\operatorname{Pr}\left(\Delta_{i}=1 \mid T_{i}^{*}>\bar{T}\right)
$$


where $\bar{T}$ is some positive number. Correspondingly, (A.4) now becomes

$$
\operatorname{Pr}\left(\Delta_{i}=1 \mid D_{i}=1, T_{i} ; \bar{T}\right)=1-F_{\varepsilon \mid \varepsilon \leq T_{i}}(-\bar{T})+\left[1-F_{T}(-\bar{T})\right] \int_{-\infty}^{-\bar{T}} \frac{f_{\varepsilon \mid \varepsilon \leq T_{i}}(\varepsilon)}{1-F_{T}(\varepsilon)} d \varepsilon \equiv p\left(\bar{T} ; T_{i}\right)
$$

and

$$
\operatorname{Pr}\left(\Delta_{i}=1 \mid D_{i}=1\right)=\int_{T_{i}} p\left(\bar{T} ; T_{i}\right) d F\left(T_{i}\right)
$$

It is easy to prove that

$$
\frac{d p\left(\bar{T} ; T_{i}\right)}{d \bar{T}} \geq 0
$$

Thus, when the threshold is lifted, we should expect the subsample $D_{i}$ as defined to enclose more and more genuinely $\Delta_{i}=1$ observations, and the attenuation bias for $\beta_{1}$ would be alleviated. However, also associated with lifting thresholds, the sample size of $D_{i}=1$ is shrinking, which may lead to imprecise and less robust estimates.

\section{B Proof of Identification of Two-regime Switching Regressions with Arbitrary Regime Error Term Distributions}

Yakowitz and Spragins (1968) establish the result that finite-mixtures of normals can be identified up to "label switching". Ferguson (1983) proves that any arbitrary distribution on the real line can be indefinitely approximated by a mixture of a countable number of normal distributions subject to label switching, i.e., for any density function $f(x)$,

$$
f(x)=\sum_{i=1}^{\infty} c_{i} \phi\left(x \mid \mu_{i}, \sigma_{i}^{2}\right), \quad 0<c_{i}<1, \quad \sum_{i=1}^{\infty} c_{i}=1
$$

These two results, coupled with the Monotonicity Condition, underly our sketch of proof of identification.

To fix ideas, suppose each of the error terms in (2.9), $U_{1}$ and $U_{0}$, can be adequately 
described by a two-component normal mixtures:

$$
\begin{aligned}
& f\left(u_{1}\right)=c_{1} \phi\left(u_{1} \mid \mu_{1}, \sigma_{1}^{2}\right)+\left(1-c_{1}\right) \phi\left(u_{1} \mid \mu_{2}, \sigma_{2}^{2}\right) \\
& f\left(u_{0}\right)=c_{0} \phi\left(u_{0} \mid \mu_{3}, \sigma_{3}^{2}\right)+\left(1-c_{0}\right) \phi\left(u_{0} \mid \mu_{4}, \sigma_{4}^{2}\right)
\end{aligned}
$$

"Label switching" means, for instance, in (B.1a), we do not really care which weight is labeled as $c_{1}$ and which as $1-c_{1}$, or which is labeled as $\left(\mu_{1}, \sigma_{1}\right)$ and which as $\left(\mu_{0}, \sigma_{0}\right)$, because there is no meaningful interpretation attached to each label. A simple rule, such as $c_{1} \leq 0.5$, or $\mu_{1} \leq \mu_{2}$, would help anchor the labels if so desired. Another notable fact from either (B.1a) or (B.1b) is that even without label identification, the matching between weights and normals is never confused. We also exploit this fact in what follows.

This irrelevance of labels is subject to change when we refer the label 1 to the unconstrained group as in our intergenerational mobility model. Due to the imperfect classification by $D$, the subgroup of observations $D=1$ includes cases drawn from both $U_{1}$ and $U_{0}$. Consequently, the distribution of the error term for $D=1$, denoted by $\widetilde{U}_{1}$, is in turn a mixture of $U_{1}$ and $U_{0}\left(\right.$ recall that $\left.p_{1}=\operatorname{Pr}(\Delta=1 \mid D=1)\right)$ :

$$
\begin{aligned}
f\left(\widetilde{u}_{1}\right) & =p_{1} f\left(u_{1}\right)+\left(1-p_{1}\right) f\left(u_{0}\right) \\
& =p_{1}\left[c_{1} \phi\left(\mu_{1}, \sigma_{1}^{2}\right)+\left(1-c_{1}\right) \phi\left(\mu_{2}, \sigma_{2}^{2}\right)\right]+\left(1-p_{1}\right)\left[c_{0} \phi\left(\mu_{3}, \sigma_{3}^{2}\right)+\left(1-c_{0}\right) \phi\left(\mu_{4}, \sigma_{4}^{2}\right)\right]
\end{aligned}
$$

Even though the label switching between $c_{i}$ and $1-c_{i}(i=0,1)$ is innocuous, we have to ascertain which is $p_{1}$ as opposed to $1-p_{1}$ due to the meaning of the label 1 in $p_{1}$.

(B.2) is a mixture of four normals that can still be identified up to labels, thus four weights are obtained alongside with four different sets of $\left(\mu_{i}, \sigma_{i}\right)$, denoted by $\left(a_{1}, \widetilde{a}_{2}, \widetilde{a}_{3}, \widetilde{a}_{4}\right)$. However, nothing is known about which of them corresponds to which of $\left(p_{1} c_{1}, p_{1}\left(1-c_{1}\right),\left(1-p_{1}\right) c_{0},(1-\right.$ $\left.\left.p_{1}\right)\left(1-c_{0}\right)\right)$

Likewise, the distribution of the error term for $D=0$ has a similar form $\left(p_{0}=\operatorname{Pr}(\Delta=0 \mid\right.$ 
$D=0))$ :

$$
\begin{aligned}
f\left(\widetilde{u}_{0}\right) & =\left(1-p_{0}\right) f\left(u_{1}\right)+p_{0} f\left(u_{0}\right) \\
& =\left(1-p_{0}\right)\left[c_{1} \phi\left(\mu_{1}, \sigma_{1}^{2}\right)+\left(1-c_{1}\right) \phi\left(\mu_{2}, \sigma_{2}^{2}\right)\right]+p_{0}\left[c_{0} \phi\left(\mu_{3}, \sigma_{3}^{2}\right)+\left(1-c_{0}\right) \phi\left(\mu_{4}, \sigma_{4}^{2}\right)\right]
\end{aligned}
$$

from which we can obtain $\left(\widetilde{b}_{1}, \widetilde{b}_{2}, \widetilde{b}_{3}, \widetilde{b}_{4}\right)$. Notice that the same subscript $i$ in $\widetilde{a}_{i}$ and $\widetilde{b}_{i}$ indicates they are associated with the same normal component of the mixture.

An examination of the ratios of $\widetilde{a}_{i}$ and $\widetilde{b}_{i}(i=1,2,3,4)$ reveals that they can only take

either value of: $\frac{p_{1}}{1-p_{0}}$ and $\frac{1-p_{1}}{p_{0}}$, from which we can solve out two unknowns. The solution of these two unknowns (denoted by $\widetilde{p}_{1}$ and $\widetilde{p}_{0}$ ) still suffers from the unidentification of labels, because we are yet to distinguish between the following two possibilities:

$$
\begin{array}{cl}
\widetilde{p}_{1}=p_{1}, & \widetilde{p}_{0}=p_{0} \\
\widetilde{p}_{1}=1-p_{1}, & \widetilde{p}_{0}=1-p_{0}
\end{array}
$$

Here is when the Monotonicity Condition shows its power: only one of (B.4a) and (B.4b) will satisfy the condition, which helps anchor the labels of $p_{1}$ and $p_{0}$. After this step, given the information of $p_{1}$ and $p_{0}, c_{i}(i=1,0)$ can be subsequently recovered from the fact that $c_{i}$ and $1-c_{i}$ are associated with the same normal components that $p_{j}$ or $1-p_{j}(j=1,0)$ is associated with, from either (B.2) or (B.3). Therefore the underlying distributions of $U_{1}$ and $U_{0}$ are completely recovered. The same line of reasoning in this proof can be extended to the case of more than two normal mixture components in $U_{1}$ or $U_{0}$.

\section{Implementation of Switching Regression Estimation}

For the sake of illustration, we assume $U_{j}(j=0,1)$ are normals:

$$
U_{j} \sim \mathcal{N}\left(0, \sigma_{j}^{2}\right) \quad(j=0,1)
$$


Non-normal distributions of $U_{j}$ only involve decomposing it further into mixture of normals. Then, the likelihood function is

$$
\mathbf{L}=\prod_{i}\left[\phi_{1}(\cdot) p_{1}+\phi_{0}(\cdot)\left(1-p_{1}\right)\right]^{D_{i}}\left[\phi_{1}(\cdot)\left(1-p_{0}\right)+\phi_{0}(\cdot) p_{0}\right]^{1-D_{i}}
$$

where $\phi_{j}(\cdot)$ is the PDF of $U_{j}$.

To make the model parsimonious, we write $p_{1}$ and $p_{0}$ as a binary function of $D_{i}, F\left(D_{i}\right)$, such that $F(1)=p_{1}$ and $F(0)=1-p_{0}$. We choose $F\left(D_{i}\right)=\frac{1}{1+\exp \left(\gamma_{0}+\gamma_{1} D_{i}\right)}$. Given the functional form of $F(\cdot)$, if $\gamma_{1}<0$, then $F(1)>F(0)$, which means receiving a sizable inheritance/gift will be more likely to be classified into the group whose estimates are indexed by 1 . Therefore, by the Monotonicity Condition, this group should be labeled as the unconstrained group. $F(\cdot)$ can include more than one switching variable, as long as the Monotonicity Condition is applicable to at least one of these variables to ensure identifiability. The likelihood function now becomes

$$
\mathbf{L}=\prod_{i}\left[\phi_{1}(\cdot) F\left(D_{i}\right)+\phi_{0}(\cdot)\left(1-F\left(D_{i}\right)\right)\right]
$$

A well-known challenge of maximizing the likelihood function like (C.2) is that, when $\sigma$ goes to zero, the value of likelihood function explodes, which does not constitute a valid estimate. There are at least two ways of getting around this issue. For the first, Kiefer (1978) proves that the likelihood equation (C.2) has a consistent and asymptotically efficient root, and suggests using the method of moment generating functions as laid out in Quandt and Ramsey (1978) to find out the initial consistent estimate. Schmidt (1982) improves Quandt and Ramsey's (1978) estimator by demonstrating that the generalized method of moments applied to the aforementioned moment generating function performs better. For the second, Hathaway (1985) shows that simple constraints on $\sigma_{i}$ that the relative ratios of either one to the other cannot be too small can help rule out spurious local maximizers. That is, if the 
constraints

$$
\min _{j, k}\left(\sigma_{j} / \sigma_{k}\right) \geq c>0 \quad \forall j, k
$$

are imposed, where $c$ is a sufficiently small number and $j, k$ are indexing any two of regime error terms, then the maximum likelihood problem is well defined in optimization, and the global solution is strongly consistent.

We follow Hathaway's (1985) method for its simplicity in implementation. We pick the constraint parameter $c=0.0067$ which is adequately small for the iterations to converge. After obtaining the initial consistent estimates through this step, we feed them as initial values into a subsequent, more refined MLE step.

\section{Figures and Tables}

Figure 1: Density plot of actual inheritances/gifts received by adult children up to 2003 in PSID intergenerational sample

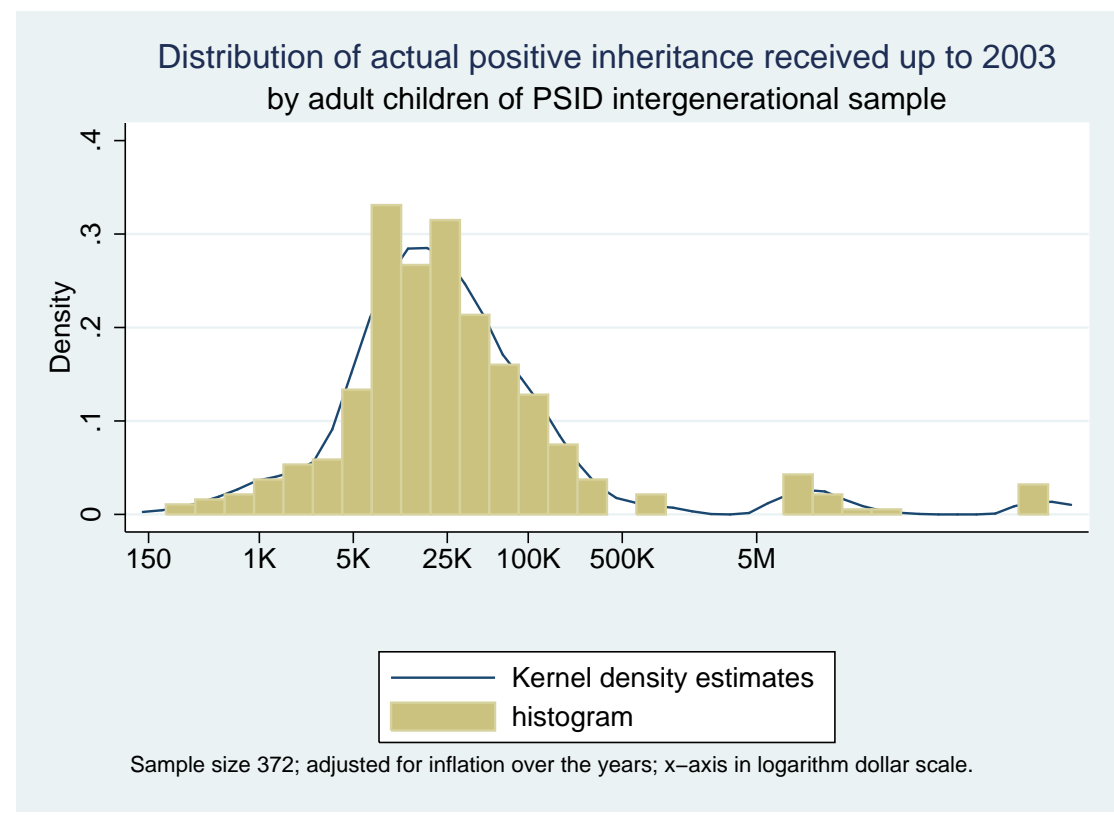


Figure 2: Densities of fitted and actual adult children's consumption: classification using expected inheritance indicator

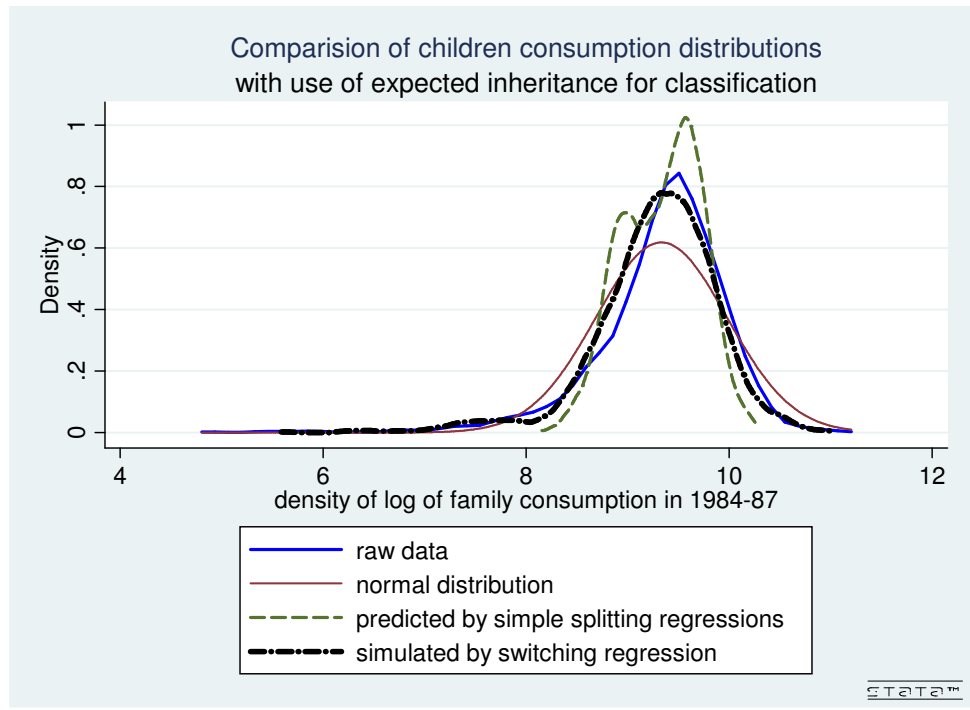

Figure 3: Densities of fitted and actual adult children's consumption: classification using actual inheritance/gift indicator

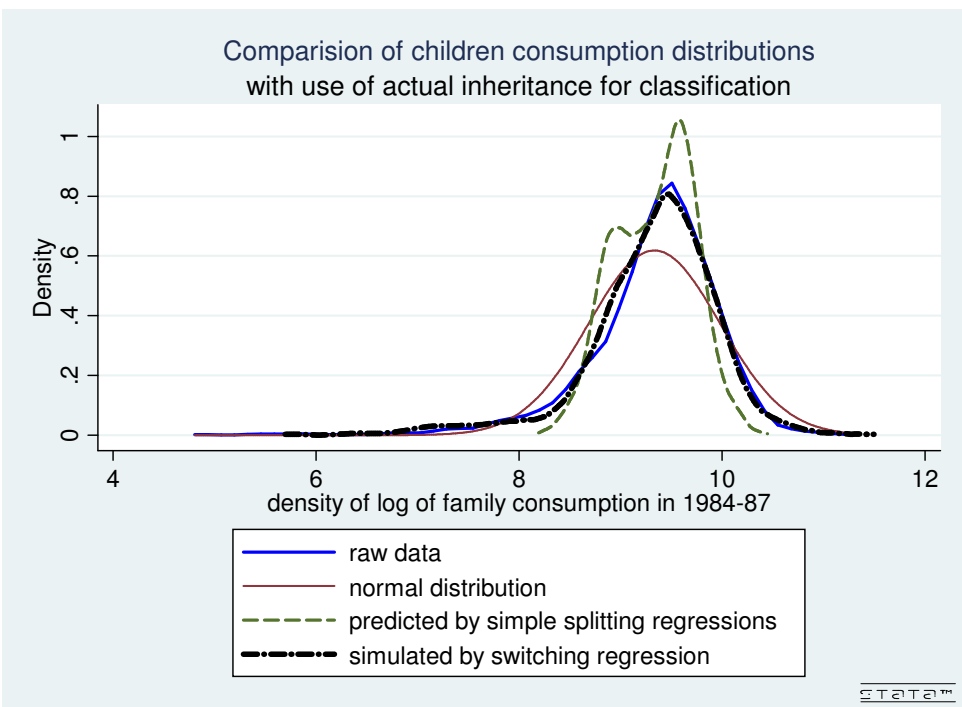


Table 1: Distribution of expected and actual inheritance/gift by size

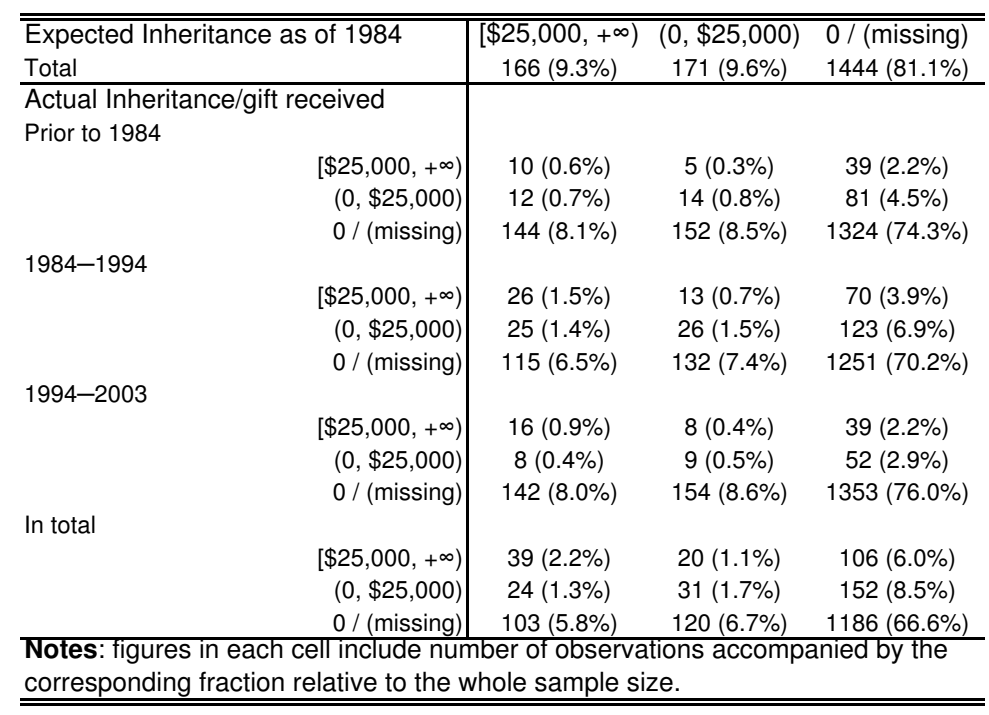

Table 2: Summary statistics of relevant variables by expected and actual inheritance/gift size in PSID intergenerational sample

\begin{tabular}{|c|c|c|c|c|c|}
\hline \multirow[t]{2}{*}{ Variable } & \multirow[t]{2}{*}{ all } & \multicolumn{2}{|c|}{ expected Inheritance $\geq \$ 25,000$} & \multicolumn{2}{|c|}{ expected Inheritance $<\$ 25,000$} \\
\hline & & act. Inheritance $\geq \$ 25,000$ & act. Inheritance $<\$ 25,000$ & act. Inheritance $\geq \$ 25,000$ & act. Inheritance $<\$ 25,000$ \\
\hline \multirow[t]{2}{*}{ Parent's age ${ }^{(a)}$} & 40.3 & 43.0 & 42.0 & 41.6 & 39.9 \\
\hline & $(7.4)$ & $(7.9)$ & (7.3) & $(7.8)$ & (7.3) \\
\hline \multirow[t]{2}{*}{ Parent's income ${ }^{(b)}$} & 28661.59 & 41407.35 & 29366.85 & 36942.06 & 27452.50 \\
\hline & $(19880.37)$ & (27667.92) & (17224.92) & $(17970.01)$ & $(19523.75)$ \\
\hline \multirow[t]{2}{*}{ Parent's consumption ${ }^{(b)}$} & 17224.65 & 21386.75 & 17644.44 & 21635.12 & 16694.53 \\
\hline & $(7577.35)$ & $(8167.39)$ & $(7187.16)$ & $(9220.81)$ & $(7312.35)$ \\
\hline \multirow[t]{2}{*}{ Parent's wage ${ }^{(c)}$} & 10.18 & 13.44 & 10.07 & 13.33 & 9.82 \\
\hline & (7.41) & (7.85) & $(6.10)$ & $(6.77)$ & (7.49) \\
\hline \multirow[t]{2}{*}{ Parent's education achievement ${ }^{(d)}$} & 10.44 & 12.39 & 10.73 & 12.04 & 10.21 \\
\hline & (3.67) & $(4.08)$ & (3.59) & (3.41) & (3.62) \\
\hline Child's age ${ }^{(e)}$ & 31.3 & 31.9 & 31.8 & 30.6 & 31.3 \\
\hline \multirow{2}{*}{ Child's income ${ }^{(b)}$} & 27283.13 & 40043.55 & 32050.94 & $\begin{array}{c}(2.9) \\
33447.17\end{array}$ & 25791.74 \\
\hline & (19729.82) & (16881.34) & (25822.68) & (20496.73) & (18688.22) \\
\hline Child's consumption ${ }^{(b)}$ & $\begin{array}{l}13334.61 \\
(7274.90)\end{array}$ & $\begin{array}{l}19162.79 \\
(8560.21)\end{array}$ & $\begin{array}{l}14779.99 \\
(8894.92)\end{array}$ & $\begin{array}{l}16274.73 \\
(8270.92)\end{array}$ & $\begin{array}{l}12721.57 \\
(6756.71)\end{array}$ \\
\hline Child's wage ${ }^{(c)}$ & $\begin{array}{c}8.24 \\
(5.36)\end{array}$ & $\begin{array}{c}9.34 \\
(5.22)\end{array}$ & $\begin{array}{c}9.21 \\
(7.59)\end{array}$ & $\begin{array}{c}9.48 \\
(5.48)\end{array}$ & $\begin{array}{c}8.00 \\
(5.04)\end{array}$ \\
\hline \multirow[t]{2}{*}{ Child's education achievement ${ }^{(\mathrm{d})}$} & 13.21 & 14.29 & 13.36 & 14.18 & 13.08 \\
\hline & $(2.17)$ & $(2.10)$ & $(2.23)$ & $(2.15)$ & $(2.14)$ \\
\hline
\end{tabular}


Table 3: Switching regression and simple sample splitting regressions of intergenerational consumption persistence: classification based on expected inheritances

\begin{tabular}{|c|c|c|c|c|}
\hline \multicolumn{5}{|c|}{ Consumption persistence regression: classification according to expected inheritances } \\
\hline \multirow[t]{2}{*}{ Estimation Methods } & \multicolumn{2}{|c|}{ Switching regression } & \multicolumn{2}{|c|}{ Simple sample splitting ${ }^{(a)}$} \\
\hline & $\Delta=1^{(b)}$ & $\Delta=0^{(b)}$ & $D_{e}=1^{(c)}$ & $D_{e}=0^{(c)}$ \\
\hline parental consumption ${ }^{(d)}$ & $\begin{array}{c}\mathbf{0 . 4 3 9 4} \\
(0.0237)\end{array}$ & $\begin{array}{c}1.0527 \\
(0.1425)\end{array}$ & $\begin{array}{c}\mathbf{0 . 4 4 9 1} \\
(0.0770)\end{array}$ & $\begin{array}{c}\mathbf{0 . 5 4 8 7} \\
(0.0358)\end{array}$ \\
\hline daughter dummy & $\begin{array}{l}-0.0400 \\
(0.0207)\end{array}$ & $\begin{array}{c}0.3524 \\
(0.1146)\end{array}$ & $\begin{array}{c}0.0282 \\
(0.0655)\end{array}$ & $\begin{array}{l}-0.0232 \\
(0.0280)\end{array}$ \\
\hline parental marital status & $\begin{array}{l}-0.0210 \\
(0.0066)\end{array}$ & $\begin{array}{c}0.0205 \\
(0.0362)\end{array}$ & $\begin{array}{l}-0.0101 \\
(0.0225)\end{array}$ & $\begin{array}{l}-0.0076 \\
(0.0117)\end{array}$ \\
\hline child's marital status & $\begin{array}{c}0.4465 \\
(0.0246)\end{array}$ & $\begin{array}{c}1.3008 \\
(0.1438)\end{array}$ & $\begin{array}{c}0.6222 \\
(0.0990)\end{array}$ & $\begin{array}{c}0.6058 \\
(0.0345)\end{array}$ \\
\hline parent's age $\left(\times 10^{-1}\right)^{(e)}$ & $\begin{array}{l}-0.1130 \\
(0.1157)\end{array}$ & $\begin{array}{l}-0.1810 \\
(0.7600)\end{array}$ & $\begin{array}{c}0.7487 \\
(0.4141)\end{array}$ & $\begin{array}{l}-0.1703 \\
(0.1604)\end{array}$ \\
\hline parent's age squared $\left(\times 10^{-3}\right)^{(\mathrm{e})}$ & $\begin{array}{l}0.1287 \\
(0.1359)\end{array}$ & $\begin{array}{l}0.2534 \\
(0.8964)\end{array}$ & $\begin{array}{l}-0.8822 \\
(0.4516)\end{array}$ & $\begin{array}{c}0.1922 \\
(0.1856)\end{array}$ \\
\hline child's age $\left(\times 10^{-1}\right)^{(e)}$ & $\begin{array}{l}-1.0510 \\
(0.8404)\end{array}$ & $\begin{array}{c}5.2938 \\
(4.1824)\end{array}$ & $\begin{array}{c}0.4896 \\
(3.2374)\end{array}$ & $\begin{array}{c}-0.2741 \\
(1.2167)\end{array}$ \\
\hline child's age squared $\left(\times 10^{-3}\right)^{(\mathrm{e})}$ & $\begin{array}{l}2.0703 \\
(1.3425)\end{array}$ & $\begin{array}{l}-8.2160 \\
(6.6167)\end{array}$ & $\begin{array}{l}-0.1292 \\
(5.1189)\end{array}$ & $\begin{array}{c}0.6997 \\
(1.9581)\end{array}$ \\
\hline (intercept) & $\begin{array}{c}6.4907 \\
(1.3313)\end{array}$ & $\begin{array}{l}-10.540 \\
(6.7839)\end{array}$ & $\begin{array}{c}1.7653 \\
(5.1462)\end{array}$ & $\begin{array}{c}4.2185 \\
(1.9292)\end{array}$ \\
\hline$\sigma_{U}$ & $\begin{array}{c}0.3547 \\
(0.0093)\end{array}$ & $\begin{array}{c}0.6616 \\
(0.0392)\end{array}$ & & \\
\hline $\mathrm{Y}_{0}$ & & & & \\
\hline$Y_{1}$ & & & & \\
\hline maximized loglikelihood & & & & \\
\hline $\operatorname{Pr}\left(\Delta \mid D_{e}=1\right)^{(f)}$ & 0.9167 & 0.0933 & & \\
\hline $\operatorname{Pr}\left(\Delta \mid \mathrm{D}_{\mathrm{e}}=0\right)^{(\mathrm{f})}$ & 0.8423 & 0.1577 & & \\
\hline
\end{tabular}

Notes: sample size 1781; dependent variable: adult child's logarithm of consumption; standard error in parenthesis; expected inheritance indicator is used for identifying which set of parameters in the switching regression corresponds to the regime of borrowing constrained $(\Delta=0)$. See text for details. (a) linear regressions for each subsample with standard error clustered by parental family identifiers; (b) 1--"unconstrained"; 0--"constrained"; (c) 1--expected inheritance greater than $\$ 25,000$ (219 cases); 0--expected inheritance less than $\$ 25,000$ (1562 cases); (d) consumption is the logrithm of multi-year average of Skinner(1987) consumption measure; (e) parent's age is the household head's age as of 1967; child's age is the child's age as of 1987; (f) probability of being "unconstrained" or "constrained" conditional on the value of the indicator $D_{e}$; calculated from $\Phi\left(\mathrm{\gamma} 0+\mathrm{\gamma} 1 \mathrm{D}_{\mathrm{e}}\right)$, where $\Phi($.$) is the CDF of standard normal distribution.$ 
Table 4: Switching regression and simple sample splitting regressions of intergenerational consumption persistence: classification based on actual inheritances/gifts

\begin{tabular}{|c|c|c|c|c|}
\hline \multicolumn{5}{|c|}{ Consumption persistence regression: classification according to actual inheritances/gift } \\
\hline \multirow[t]{2}{*}{ Variable } & \multicolumn{2}{|c|}{ Switching regression } & \multicolumn{2}{|c|}{ Simple sample splitting ${ }^{(a)}$} \\
\hline & $\Delta=1^{(D)}$ & $\Delta=0^{(D)}$ & $D_{a}=1^{(c)}$ & $D_{a}=0^{(c)}$ \\
\hline parental consumption $^{(\mathrm{d})}$ & $\begin{array}{c}0.4398 \\
(0.0236)\end{array}$ & $\begin{array}{c}\mathbf{1 . 0 1 7 6} \\
(0.1376)\end{array}$ & $\begin{array}{c}\mathbf{0 . 6 2 5 4} \\
(0.0948)\end{array}$ & $\begin{array}{c}\mathbf{0 . 5 2 2 9} \\
(0.0363)\end{array}$ \\
\hline daughter dummy & $\begin{array}{l}-0.0400 \\
(0.0206)\end{array}$ & $\begin{array}{c}0.3263 \\
(0.1151)\end{array}$ & $\begin{array}{l}-0.0086 \\
(0.0713)\end{array}$ & $\begin{array}{l}-0.0289 \\
(0.0272)\end{array}$ \\
\hline parental marital status & $\begin{array}{l}-0.0220 \\
(0.0066)\end{array}$ & $\begin{array}{c}0.0240 \\
(0.0360)\end{array}$ & $\begin{array}{l}-0.0506 \\
(0.0306)\end{array}$ & $\begin{array}{l}-0.0065 \\
(0.0112)\end{array}$ \\
\hline child's marital status & $\begin{array}{c}0.4474 \\
(0.0245)\end{array}$ & $\begin{array}{c}1.2824 \\
(0.1437)\end{array}$ & $\begin{array}{c}0.5212 \\
(0.1056)\end{array}$ & $\begin{array}{c}0.6110 \\
(0.0339)\end{array}$ \\
\hline parent's age $\left(\times 10^{-1}\right)^{(\mathrm{e})}$ & $\begin{array}{l}-0.1130 \\
(0.1148)\end{array}$ & $\begin{array}{l}-0.2170 \\
(0.7710)\end{array}$ & $\begin{array}{l}-0.2391 \\
(0.3791)\end{array}$ & $\begin{array}{l}-0.0691 \\
(0.1609)\end{array}$ \\
\hline parent's age squared $\left(\times 10^{-3}\right)^{(\mathrm{e})}$ & $\begin{array}{l}0.1285 \\
(0.1346)\end{array}$ & $\begin{array}{l}0.2854 \\
(0.9063)\end{array}$ & $\begin{array}{c}0.2538 \\
(0.4260)\end{array}$ & $\begin{array}{c}0.0675 \\
(0.1858)\end{array}$ \\
\hline child's age $\left(\times 10^{-1}\right)^{(\mathrm{e})}$ & $\begin{array}{l}-1.1060 \\
(0.8388)\end{array}$ & $\begin{array}{c}4.4107 \\
(4.1255)\end{array}$ & $\begin{array}{c}1.0696 \\
(2.8681)\end{array}$ & $\begin{array}{c}-0.4862 \\
(1.2236)\end{array}$ \\
\hline child's age squared $\left(\times 10^{-3}\right)^{(\mathrm{e})}$ & $\begin{array}{l}2.1587 \\
(1.3412)\end{array}$ & $\begin{array}{l}-6.7650 \\
(6.4890)\end{array}$ & $\begin{array}{l}-1.0324 \\
(4.5347)\end{array}$ & $\begin{array}{c}1.0615 \\
(1.9639)\end{array}$ \\
\hline (intercept) & $\begin{array}{c}6.5716 \\
(1.3291)\end{array}$ & $\begin{array}{c}-8.762 \\
(6.5981)\end{array}$ & $\begin{array}{c}1.4808 \\
(4.3258)\end{array}$ & $\begin{array}{c}4.5718 \\
(1.9509)\end{array}$ \\
\hline$\sigma_{U}$ & $\begin{array}{c}0.3534 \\
(0.0092)\end{array}$ & $\begin{array}{c}0.6656 \\
(0.0372)\end{array}$ & & \\
\hline$Y_{0}$ & & & & \\
\hline 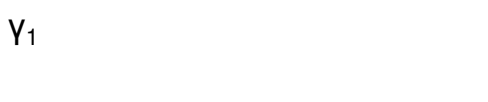 & & & & \\
\hline maximized loglikelihood & & & & \\
\hline $\operatorname{Pr}\left(\Delta \mid D_{\mathrm{a}}=1\right)^{(\mathrm{f})}$ & 0.9284 & 0.0716 & & \\
\hline $\operatorname{Pr}\left(\Delta \mid D_{a}=0\right)^{(f)}$ & 0.8399 & 0.1601 & & \\
\hline
\end{tabular}

Notes: sample size 1781; dependent variable: adult child's logarithm of consumption; standard error in parenthesis; actual inheritance indicator is used for identifying which set of parameters in the switching regression corresponds to the regime of borrowing constrained $(\Delta=0)$. See text for details. (a) linear regressions for each subsample with standard error clustered by parental family identifiers; (b) 1--"unconstrained"; 0--"constrained"; (c) 1--received actual inheritances/gifts greater than $\$ 25,000$ (165 cases); 0--received actual inheritances/gifts less than $\$ 25,000$ (1616 cases); (d) consumption is the logrithm of multi-year average of Skinner(1987) consumption measure; (e) parent's age is the household head's age as of 1967; child's age is the child's age as of 1987; (f) probability of being "unconstrained" or "constrained" conditional on the value of proxy indicator $\mathrm{D}_{\mathrm{a}}$ calculated from $\Phi\left(\mathrm{y} 0+\mathrm{\gamma} 1 \mathrm{D}_{\mathrm{a}}\right)$, where $\Phi($.$) is the CDF of standard normal distribution.$ 
Table 5: Estimated consumption persistence by using alternative cut-offs of actual inheritances/gifts for constructing the classification indicator: simple sample splitting and switching regressions

\begin{tabular}{cccccccc}
\hline \hline Threshold value & $\$ 0$ & $\$ 5 k$ & $\$ 10 k$ & $\$ 25 k$ & $\$ 30 k$ & $\$ 40 k$ & $\$ 50 k$ \\
Sample Size $(D=1)$ & 372 & 329 & 265 & 165 & 141 & 121 & 102 \\
\hline & Simple sample splitting regression estimates \\
$\beta_{1}$ (unconstrained) & 0.5712 & 0.5449 & 0.5717 & 0.6254 & 0.6514 & 0.6905 & 0.6421 \\
& $(0.0591)$ & $(0.0640)$ & $(0.0706)$ & $(0.0893)$ & $(0.0978)$ & $(0.1104)$ & $(0.1214)$ \\
$\beta_{0}$ (constrained) & 0.5067 & 0.5126 & 0.5157 & 0.5229 & 0.5239 & 0.5278 & 0.5328 \\
& $(0.0360)$ & $(0.0351)$ & $(0.0338)$ & $(0.0324)$ & $(0.0322)$ & $(0.0318)$ & $(0.0316)$ \\
\hline \multicolumn{7}{c}{ Switching regression estimates } \\
$\beta_{1}$ (unconstrained) & 0.4401 & 0.4439 & 0.4426 & 0.4398 & 0.4396 & 0.4387 & 0.4353 \\
& $(0.0236)$ & $(0.0237)$ & $(0.0237)$ & $(0.0236)$ & $(0.0236)$ & $(0.0237)$ & $(0.0236)$ \\
$\beta_{0}$ (constrained) & 0.9889 & 0.9936 & 1.0061 & 1.0176 & 1.0269 & 0.9994 & 1.0461 \\
& $(0.1408)$ & $(0.1417)$ & $(0.1390)$ & $(0.1376)$ & $(0.1310)$ & $(0.1368)$ & $(0.1597)$ \\
$\operatorname{Pr}(\Delta=1 \mid D=1)$ & 0.9246 & 0.9220 & 0.9274 & 0.9284 & 0.9057 & 0.8876 & 0.9077 \\
$\operatorname{Pr}(\Delta=0 \mid D=1)$ & 0.0754 & 0.0780 & 0.0726 & 0.0716 & 0.0943 & 0.1124 & 0.0923 \\
$\operatorname{Pr}(\Delta=1 \mid D=0)$ & 0.8329 & 0.8411 & 0.8415 & 0.8399 & 0.8435 & 0.8419 & 0.8373 \\
$\operatorname{Pr}(\Delta=0 \mid D=0)$ & 0.1671 & 0.1589 & 0.1585 & 0.1627 & 0.1565 & 0.1581 & 0.1366 \\
\hline \hline
\end{tabular}

Notes: Standard error in parenthesis. $D=1$ if received actual inheritances/gifts are greater than the specified cutoff value, and $D=0$ if otherwise. 
Table 6: Switching regression estimates of intergenerational consumption persistence: $\log$ of actual inheritances/gifts in the switching equation

\begin{tabular}{|c|c|c|c|}
\hline \multicolumn{4}{|c|}{ Consumption persistence switching regression: log of actual inheritances/gifts } \\
\hline \multirow[t]{2}{*}{ Variable } & \multicolumn{2}{|c|}{ Regime equation } & \multirow{2}{*}{$\frac{\text { Switching equation }}{\operatorname{Prob}(\Delta=1 \mid \text { D })^{(b)}}$} \\
\hline & $\Delta=1^{(a)}$ & $\Delta=0^{(\mathrm{a})}$ & \\
\hline parental consumption $^{(\mathrm{c})}$ & $\begin{array}{c}\mathbf{0 . 4 4 4 2} \\
(0.0266)\end{array}$ & $\begin{array}{c}\mathbf{0 . 9 8 3 2} \\
(0.2824)\end{array}$ & \multirow{11}{*}{$\begin{array}{l}-0.0838 \\
(0.0426) \\
-1.6380 \\
(0.1920)\end{array}$} \\
\hline daughter dummy & $\begin{array}{l}-0.0378 \\
(0.0207)\end{array}$ & $\begin{array}{c}0.3421 \\
(0.1188)\end{array}$ & \\
\hline parental marital status & $\begin{array}{l}-0.0215 \\
(0.0072)\end{array}$ & $\begin{array}{c}0.0204 \\
(0.0370)\end{array}$ & \\
\hline child's marital status & $\begin{array}{c}0.4493 \\
(0.0254)\end{array}$ & $\begin{array}{c}1.3048 \\
(0.1469)\end{array}$ & \\
\hline parent's age $^{(\mathrm{d})}$ & $\begin{array}{l}-0.0108 \\
(0.0126)\end{array}$ & $\begin{array}{l}-0.0224 \\
(0.0517)\end{array}$ & \\
\hline parent's age squared & $\begin{array}{l}0.0001 \\
(0.0001)\end{array}$ & $\begin{array}{l}0.0003 \\
(0.0006)\end{array}$ & \\
\hline child's age ${ }^{(d)}$ & $\begin{array}{l}-0.1223 \\
(0.0877)\end{array}$ & $\begin{array}{c}0.5812 \\
(0.5609)\end{array}$ & \\
\hline child's age squared & $\begin{array}{l}0.0024 \\
(0.0014)\end{array}$ & $\begin{array}{l}-0.0091 \\
(0.0090)\end{array}$ & \\
\hline log of actual inheritances/gifts ${ }^{(e)}$ & - & & \\
\hline (Constant) & $\begin{array}{c}6.6932 \\
(1.3469)\end{array}$ & $\begin{array}{l}-10.556 \\
(8.6517)\end{array}$ & \\
\hline$\sigma_{U}$ & $\begin{array}{r}0.3565 \\
(0.0118) \\
\end{array}$ & $\begin{array}{c}0.6606 \\
(0.0413) \\
\end{array}$ & \\
\hline \multicolumn{4}{|l|}{ sample average of: } \\
\hline $\begin{array}{r}\text { preaicted } \operatorname{Prob}(\Delta=1) \\
\text { predicted } \operatorname{Prob}(\Delta=1 \mid \text { actual inheritances }>0)^{(f)}\end{array}$ & \multicolumn{3}{|c|}{0.9231} \\
\hline predicted $\operatorname{Prob}(\Delta=1 \mid \text { actual inheritances }=0)^{(f)}$ & \multicolumn{3}{|c|}{0.8373} \\
\hline maximized loglikelihood & \multicolumn{3}{|c|}{-1106.67} \\
\hline \multicolumn{4}{|c|}{$\begin{array}{l}\text { Notes: sample size } 1781 \text {; dependent variable: adult child's logarithm of consumption; standard error in } \\
\text { parenthesis. } \\
\text { (a) 1--"unconstrained"; } 0 \text {--"constrained"; } \\
\text { (b) probability of being truly "unconstrained" or "constrained" conditional on the value of a vector of variables } \\
\text { D, in the form of } F(D y)=1 /(1+\exp (D y)) \text { in accordance with the identification of unconstrained group; }\end{array}$} \\
\hline \multicolumn{4}{|c|}{ (c) consumption is the logrithm of multi-year average of Skinner(1987) consumption measure for a household; } \\
\hline \multicolumn{4}{|c|}{$\begin{array}{l}\text { (d) parent's age is the household head's age as of } 1967 \text {; child's age is the child's age as of } 1987 \text {; } \\
\text { (e) continuous variable, computed as log of ammount of actually received inheritances/gifts; } \\
\text { (f) computed as the predicted value based on the estimated coefficients of switching equation. }\end{array}$} \\
\hline
\end{tabular}


Table 7: Switching regression estimates of intergenerational consumption persistence: alternative sets of switching variables

\begin{tabular}{|c|c|c|c|c|}
\hline & \multicolumn{4}{|c|}{ Alternative specifications of switching equation } \\
\hline & (1) & (2) & (3) & (4) \\
\hline \multicolumn{5}{|l|}{$\begin{array}{l}\text { Regime equation } \\
\Delta=1 \text { ("borrowing unconstrained group") }\end{array}$} \\
\hline parental consumption & $\begin{array}{l}0.4436^{* * *} \\
(0.0257)\end{array}$ & $\begin{array}{c}0.4351^{* * *} \\
(0.0262)\end{array}$ & $\begin{array}{c}0.4407^{* * *} \\
(0.0273)\end{array}$ & $\begin{array}{c}0.4381^{* * *} \\
(0.0256)\end{array}$ \\
\hline \multicolumn{5}{|l|}{$\Delta=0$ ("borrowing constrained group") } \\
\hline parental consumption & $\begin{array}{c}0.9009^{\star \star \star} \\
(0.1641)\end{array}$ & $\begin{array}{c}0.8209^{\star * \star} \\
(0.1551)\end{array}$ & $\begin{array}{c}0.9513^{\star \star \star} \\
(0.1615)\end{array}$ & $\begin{array}{c}0.7630^{\star \star \star} \\
(0.1664)\end{array}$ \\
\hline \multicolumn{5}{|l|}{ Switching equation ${ }^{(a)}$} \\
\hline parental savings ${ }^{(b)}$ & $\begin{array}{c}-0.9073^{\star \star *} \\
(0.2616)\end{array}$ & & & $\begin{array}{c}-0.7628^{\star * *} \\
(0.2568)\end{array}$ \\
\hline number of children in school & $\begin{array}{l}0.1585^{\star *} \\
(0.0617)\end{array}$ & & & $\begin{array}{l}0.1524^{* *} \\
(0.0640)\end{array}$ \\
\hline parental homeownership & $\begin{array}{l}-0.0765 \\
(0.2534)\end{array}$ & & & \\
\hline parental car ownership & $\begin{array}{c}-0.6504^{\star *} \\
(0.2832)\end{array}$ & & & $\begin{array}{c}-0.4246 \\
(0.2792)\end{array}$ \\
\hline parental head is nonwhite & & $\begin{array}{l}1.2903^{\star \star *} \\
(0.2704)\end{array}$ & & \\
\hline father's age above 50 & & $\begin{array}{l}0.7855^{\star *} \\
(0.3355)\end{array}$ & & $\begin{array}{l}1.0232^{* * *} \\
(0.3636)\end{array}$ \\
\hline mother's education level college and above & & $\begin{array}{l}-0.5175 \\
(0.3264)\end{array}$ & $\begin{array}{l}-0.7574^{*} \\
(0.3873)\end{array}$ & $\begin{array}{c}-0.4501 \\
(0.3364)\end{array}$ \\
\hline \multicolumn{2}{|l|}{ lots of readings at parental home ${ }^{(c)}$} & & $\begin{array}{l}-0.3275 \\
(0.3161)\end{array}$ & \\
\hline \multicolumn{2}{|l|}{ parental home in rural area ${ }^{(\mathrm{d})}$} & & $\begin{array}{c}0.1266 \\
(0.3118) \\
\end{array}$ & \\
\hline $\begin{array}{l}\text { sample average of predicted } \operatorname{Prob}(\Delta=1)^{(\mathrm{e})} \\
\text { maximized loglikelihood value }\end{array}$ & 0.8556 & 0.8478 & 0.8566 & 0.8515 \\
\hline \multicolumn{5}{|c|}{$\begin{array}{l}\text { Notes: These regressions are conducted on the full sample of } 1781 \text { parent-child pairs. The dependent variable } \\
\text { is the adult child's logarithm of consumption. The independent variables in regime equations, other than the } \\
\text { logarithm of parental consumption, are identical to those in previous tables, and their estimated coefficients are } \\
\text { omitted. Standard errors are in parentheses. }{ }^{* * *},{ }^{* *},{ }^{*} \text { indicate the statistical significance of a coefficient at } 0.01 \text {, } \\
0.05 \text {, or } 0.10 \text {, respectively. } \\
\text { (a) all the variables in the switching equation are measured in } 1968-1972 \text { when a child resided with his/her } \\
\text { parents. }\end{array}$} \\
\hline \multicolumn{5}{|c|}{$\begin{array}{l}\text { (b) }=1 \text { if parents ever saved more than two month's income in } 1968-1972 ;=0 \text { if otherwise. } \\
\text { (c) }=1 \text { if a lot of reading material was visible in the drelling uinit; }=0 \text { if otherwise. } \\
\text { (d) }=1 \text { if lived } 50 \text { miles or more from the center of a city in each year of } 1968-1972 ;=0 \text { if otherwise. } \\
\text { (e) the predicted value of } \operatorname{Prob}(\Delta=1) \text { is computed based on the estimated coefficients of switching equation. }\end{array}$} \\
\hline
\end{tabular}


Table 8: Prediction regression of actual inheritances/gifts received conditional on expected inheritances

\begin{tabular}{|c|c|}
\hline \multicolumn{2}{|c|}{ Prediction of actual inheritance/gift conditonal on expected inheritance } \\
\hline Variable & Tobit $^{(a, b)}$ \\
\hline expected Inheritances $>25000^{(c)}$ & $\begin{array}{c}8.6245^{\star \star \star} \\
(1.044)\end{array}$ \\
\hline log of parental income in $1967-1971^{(d)}$ & $\begin{array}{c}5.2678^{* \star *} \\
(0.969)\end{array}$ \\
\hline log of adult children's income in $1984-1988^{(d)}$ & $\begin{array}{l}0.3467 \\
(0.877)\end{array}$ \\
\hline log of adult children's wealth in $1984^{(\mathrm{e})}$ & $\begin{array}{c}0.4847^{\star * \star} \\
(0.118)\end{array}$ \\
\hline $\begin{array}{l}\text { adult children's education attainment } \\
\text { (measured in years) }\end{array}$ & $\begin{array}{c}0.6585^{\star * *} \\
(0.246)\end{array}$ \\
\hline adult children's homeownership in 1984-1988 & $\begin{array}{c}2.9156^{\star *} \\
(1.246)\end{array}$ \\
\hline adult children's car ownership in 1984-1988 & $\begin{array}{l}0.8955 \\
(2.672)\end{array}$ \\
\hline $\begin{array}{l}\text { average number of adult children's kids } \\
\text { (under age of } 18 \text { in 1984-1988) }\end{array}$ & $\begin{array}{l}-1.2842^{\star * \star} \\
(0.485)\end{array}$ \\
\hline $\begin{array}{l}\text { maximized loglikelihood value } \\
\text { Notes: Sample size is } 1768 \text { Denendent variak }\end{array}$ & -1937.2367 \\
\hline \multicolumn{2}{|c|}{$\begin{array}{l}\text { Notes: Sample size is } 1768 \text {. Dependent variable is adult child's log of actual inheritance } \\
\text { received. Standard error are in parentheses. }{ }^{* * *} \text {, }{ }^{* *},{ }^{*} \text { indicate the statistical significance } \\
\text { of a coefficient at } 0.01,0.05 \text {, or } 0.10 \text {, respectively. Other control variables are included } \\
\text { in the specification whose results are not shown: a dummy variable for an adult child's } \\
\text { gender; the fraction of years a parent or an adult child is being married during the years } \\
\text { when they are observed; an age quadratic for a father in } 1967 \text { and an adult child in } \\
1987 \text {. (a) standard error is clustering adjusted by parental family identifiers; (b) those } \\
\text { with zero or missing actual inheritance are treated as cencored observations in } \\
\text { estimation; (c) a dummy variable, constructed as equal to one if the expected } \\
\text { inheritance is greater than } \$ 25,000 \text { and equal to zero if less than } \$ 25,000 ;(d) \\
\text { household income is the logarithm of multi-year average of corresponding years; (e) if } \\
\text { the wealth level (w) is negative, compute it as -log }(-w) \text {. }\end{array}$} \\
\hline
\end{tabular}

